\title{
LAS RENTAS ECLESIÁSTICAS Y LOS FONDOS DE LA CAPILLA REAL DURANTE EL GOBIERNO DEL CONDESTABLE DON PEDRO DE PORTUGAL COMO «REY INTRUSO» DE ARAGÓN (1464-1466)
}

\author{
Luis Adão de Fonseca
}

1. Como el título de este trabajo indica, es nuestro propósito reflexionar sobre la utilización de las rentas eclesiásticas por el Condestable D. Pedro de Portugal durante los dos años y medio que gobierna Cataluña (desde enero de 1464 hasta junio de 1466). Se integra en un estudio de conjunto que nos proponemos realizar sobre las finanzas reales en Cataluña en el gobierno del citado príncipe portugués'.

Los problemas de tipo financiero que don Pedro tiene que afrontar desde el primer dia de su corto reinado son bien conocidos; en efecto, la tesorería real no recibe - puntual e íntegramente- las sumas acorda-

${ }^{1}$ Don Pedro, condestable de Portugal (1429-1466), es hijo del infante don Pedro, duque de Coimbra (hijo segundo del monarca portugués Iuan D), y de lsabel de Urgel, hija del conde Jaime de Urgel (uno de los candidatos preferidos en Caspe). Cuando Enrique IV de Castilla, a la sazón señor del Principado de Cataluña en contra de Juan II de Aragón, renuncia a sus pretensiones, le sucede el príncipe portugués, amparado en sus derechos como nieto del citado conde de Urgel. Sobre su gobierno como rey intruso de Aragón, véanse: J.E. MARTiNez Ferrando. Tragedia del Insigne Condestable Don Pedro de Portugal, Madrid, CSIC, 1942. así como nuestro estudio $O$ Condestável D. Pedro de Portugal, Porto, INIC. 1982. Integrados en el estudio de las finanzas reales en Cataluña en la época del Condestable, que tenemos entre manos, ya están publicados: $\propto \mathrm{A}$ assistência aos pobres na Catalunha durante o reinado do Condestavel D. Pedro como "rei intruso" de Aragón (1464-1466)w, en A pobreza e a assistencia aos pobres na Peninsula Ibérica durante a Idade Média (Lisboa 1972), Actas, vol. 1, Lisboa, Instituto de Alta Cultura, 1973, p. 401-438, «Contribueión al estudio de la política financiera del Condestable Don Pedro como Rey Intruso de Aragón (1464-1466): Ios aspectos monetarios», en Homenaje a D. José Maria Lacarra, vol. 4. Zaragoza 1977. p. 197-212; Navegación y corso en el Mediterráneo Occidental. Los portugueses a mediados del siglo XV. Pamplona, Eunsa 1978, p. 67-91; O Condestável D. Pedro de Portugal (op. cit), cap. 8 titulado Aspectos económicos e financeiros do governo de D. Pedro, p. 219-293. 
das entre la Generalidad y el Condestable en ocasión de su venida a Barcelona ${ }^{2}$.

Según parece, dichos acuerdos consideraban la contribución del cabildo y de los canónigos de Barcelona como parte de los 10.000 florines destinados a gastos militares ${ }^{3}$; su incumplimiento provocó reiteradas protestas del monarca ${ }^{4}$. Por ejemplo, en una carta del 4 de marzo de 1464 , el rey transmite a los canónigos su indignación por las dificultades surgidas. El 19 del mismo mes, don Pedro escribe a su embajador en Roma, encargándole obtener del Papa su nombramiento como canónigo de la catedral de Barcelona, como lo habían sido los anteriores soberanos, con derecho a los correspondientes emolumentos ${ }^{6}$; el conflicto abierto con el cabildo es entonces una realidad?

Los primeros indicios de una cierta mejoría en la situación aparecen en el verano de ese año, concretamente en junio". Así, por carta del 3 de septiembre sabemos que el portugués Fernando Eanes, lugarteniente del tesorero, recibe finalmente algún dinero procedente de los fondos de la Mesa Episcopal de Barcelona: 200 libras?.

La correspondencia real presenta algunos ejemplos de la utilización de cantidades procedentes de este fondo: entre septiembre de 1464 y marzo de I 466 están documentados cerca de 13.000 sueidos (cuadro I del apéndice). Pensamos que se trata de un cómputo mínimo, dada la sensación de que los dineros utilizados por el Condestable procedentes de la Mesa Episcopal de Barcelona sólo parcialmente están reflejados en la documentación de la cancillería real.

2. Un poco más complicado es un segundo problema, el de los bienes de los eclesiásticos rebeldes, o sea, aquéllos que - con razón o sin ella— son considerados partidarios del monarca legítimo Juan II.

${ }^{2} \mathrm{Cr}$. Archivo de la Corona de Aragon. Cancillería, Intrusos, reg, 21, fol. 17v-18r (en adelante sólo se indicará reg.); esta carta fue publicada por J.E. MARTiNEZ FERRANDO, op. cit. doc. 11, p. 249-250.

${ }^{3}$ Estos 10.000 florines son concedidos el 18 de enero de 1464 (Archivo de la Corona de Aragón, Generalidad, N 481 , fol. 256r-256v y s. (en adelante sólo se indicará Gen.)

${ }_{4}^{4}$ Reg. 23, fol, 4 vII ( 20 feb. 1464) y reg. 21, fol. 9r-9v (20 feb. 1464). En esta última carta. escribe el monarca af tesorero Guiliermo Setanti: «... Apres havem reebuda una vostra letra, per ta qual nos dieu que lo que toca a la ciutat en lo fet dels X M florins es be apuntat, e que als del capitol cove solicitem per letres. Diem yos que es fet. Pero, axi deien era ja apuntat, e nunca veem effecte, e nos nons contentam de paraules. Per queus encarregam si lo del capitol tardara, en lo qual pur vos pregam siau solicit, almenys lo de la ciutat portau ab vos, que molt nos es necessari....

SReg. 21, fol. 17r y 19vl; también idem, fol. 20vII y 23rll (respectivamente, del 11 y 12 del mismo mes).

${ }^{6}$ Reg. 31, fol. 6 .

7 C.' la carta posterior a A. Granell en Reg, 22, fol. 58v-59r ( 22 abr. 1465).

8 Reg. 21 , fol. $92 \mathrm{r}$ (del primero de junio); también idem, fol. $92 \mathrm{r}-92 \mathrm{v}$ y $92 \mathrm{v}$.

${ }_{9}$ Reg. 22, fol. $199 \mathrm{r}-199 \mathrm{v}$. 
Es propósito del Condestable posibilitar a la capilla real un cauce de ingresos suficientemente amplio que la liberen de la dependencia de los fondos transferidos desde la tesorería real. Pero, este deseo se concreta muy difícilmente por las dificultades encontradas en confiscar los bienes de rebeldes.

Tales dificultades se comprenderán mejor al considerar con un poco de atención las cuentas de los capellanes de don Pedro.

En lo que se refiere a la procedencia de los fondos ${ }^{10}$, el resultado es el que se muestra en el cuadro 2 del apéndice.

Comparando ahora estos ingresos con los gastos que están documentados, se comprueba que mientras Juan Martínez presenta un resultado positivo de 1.273 sueldos y 7 dineros $(4.6612 \mathrm{~d}$ de ingresos para $3.3877 \mathrm{~d}$ de gastos), por el contrario Tomás Sola prácticamente equilibra sus cuentas (5.637 $10 \mathrm{~d}$ de ingresos para $5.64710 \mathrm{~d}$ de gastos). Se pueden añadir todavía dos observaciones más: en cuanto a Juan Martínez, éste recibe su dinero fundamentalmente de la tesorería (los 609 sueldos y 5 dineros de otras procedencias poco significado tienen), por lo que conoce una situación holgada; en cuanto a Tomás Sola, el panorama es distinto, ya que éste recibe orden de gastar un total muy superior a los 2.000 sueldos que le entrega Fernando Eanes, por lo que necesita del dinero procedente del Arcedianato de la Mar para equilibrar sus cuentas.

3. Sin embargo, al analizar con un poco más de detalle los movimientos financieros de ambos capellanes, se pueden completar las observaciones anteriores.

En realidad, Juan Martínez actúa regularmente como tesorero de la capilla real en 1464. Como se ha dicho, las cantidades que recibe proceden mayoritariamente de las manos de Fernando Eanes (o sea, de la tesorería real), siendo éstas siempre entregadas con la indicación explícita del fin a que se destinan: gastos corrientes de la tesorería real. Por eso, el equilibrio de sus cuentas es perfectamente natural: cuando llegamos al final de 1464, apenas hay diferencia entre las cantidades ingresadas y las gastadas ( 3.180 sueldos y 2 dineros de ingresos y 3.222 sueldos y 7 dineros de gastos) ${ }^{11}$. Paralelamente, el panorama de ingresos y gastos de Tomás Sola del mismo año es muy similar: el dinero procede

${ }^{10}$ Véanse las cuentas de Juan Martínez y de Tomás Sola que se incluyen en el apéndice (asientos [1-60]). Todas las referencias a estos capellanes - salvo expresa indicación en nota- remiten a dichas cuentas.

11 Como puede comprenderse, habrá que restar los 260 sueldos indicados en el asiento [1]. los cuales, por las razones referidas en la nota, probablemente no llegaron a las manos del capellán. 
exclusivamente de la tesorería real con la indicación del fin a que se destinan(siemprelimosnas).

Podemos, por lo tanto, afirmar que durante el año de 1464 la capilla real no dispone de autonomía financiera, funcionando como instrumento de distribución del dinero de la tesorería destinado a gastos relacionados con la asistencia, ofertas para el culto, ceremonias religiosas, etc. Por ejemplo, el caso de los gastos de Juan Martínez en 1464 se recoge en el cuadro 3 del apéndice.

Esta situación cambia por completo el año siguiente de 1465. Con Juan Martínez, los ingresos - poco frecuentes - se diversifican, y la relación de gastos hace pensar que su vinculación a la capilla real es episódica, por haber sido destinado por el monarca hacia otras ocupaciones bien diferentes $^{12}$. Así, parece ser Tomás Sola quien se mantiene sólo con los dineros de la capilla real. Pero la posición de este capellán en la administración financiera también se altera.

El diploma que, de alguna forma, marca la pauta en este giro es una carta del Condestable fechada el 29 de septiembre de 1464, por la cual dicho Tomás Sola recibe la administración de los beneficios eclesiásticos $\operatorname{confiscados}^{13}$. Sin embargo, la puesta en práctica de esta medida presenta serias dificultades que se prolongan durante el año siguiente ${ }^{14}$. Probablemente,

12 La primera manifestación documental de este cambio de actividades de dicho capellán se sitúa en marzo de 1465, cuando él recibe el encargo real de obtener la ropa de Fernando Eanes y de inventariarla (reg. 24, fol. 10vIII, del dia 8). Posteriormente, marcha a Roma (asiento [19]), y en octubre aparece relacionado con el castillo de Hostalrich (el día 5 , es encargado de cobrar las rentas establecidas para la manutención de la guarnición de dicho castillo: reg. 26, fol, 30r-30v). Este mismo mes, es encargado de comprar pescado (asiento [39]). A la sazón, le escribe el monarca: «Nos tramettem aqui lo feel nostre Nantoni Negrell, a causa de la calç que fer manam per la obra de aqueix castell. Pregam e encarregam vos lo dirigiau en lo que sia necessari per fer la dita calç, e ell vos demanara axi en ajuda com altres que convinga. E si haura mester alguns diners per bestraure a les despeses, donau li que us demanara fins en quantitat de deu liures. Car nos aci lin havern manades donar altres deu. $\rightarrow$, en P.S.. añade en portugués: «En mandar fazer esta cal e leva la aho castelo vos encomendamos dees muita presa e trabalhees com muita diligencia. De mia manos (reg. 24, fol. 115rl). En la carta por la cual Fernando Eanes recibe orden de entregar dinero a Juan Martínez para que éste compre pescado (asiento [21]), el lugarteniente del tesorero recibe también orden de mandar al capellán un escribano de la tesorería real para que le ayude a comprar adel millor ques tropias, asf como animales para transportar el pescado adquirido. El mismo día, Fernando Eanes recibe otra orden de entregar a Juan Martínez una *ballesta gran de fust e una altra petita, les quals volem nos porte al castell de Hostalrich. E mes li compreu e doneu cent gançalles de fil de ballesta pera obs e minicio del dit castells (reg. 24, fol. 110rII).

${ }^{3}$ Reg. 21, fol. $162 \mathrm{y}-163 \mathrm{r}$. Días antes (24). Fernando Eanes, el lugarteniente del tesorero, recibió idéntico poder (reg. 23, fol. 124r-124v).

14 El 3 de enero de 1465, el monarca solicita al doctor en leyes Francisco Malet su intervención en favor de la provisión de dichos beneficios en la persona de Tomás Sola (reg. 22, fol, $25 \mathrm{r}$ ). $\mathrm{Y}$, por lo que ge puede comprobar por cartas posteriores, las dificultades se mantienen en los meses siguientes: reg. 22, fol. $28 \mathrm{r}$ ( 10 de enero) y $29 \mathrm{r}$ ( 21 de enero); particularmente interesante es la carta del 30 de abril del mismo año, por la cual Juan de 
como resultado de tales dificultades, el rey no insiste en encargar a un único funcionario la gestión de dichos fondos de los beneficios eclesiásticos confiscados: son muy numerosos los nombres que aparecen en la documentación, Pedro Exarrat ${ }^{15}$, Bernardo Planella ${ }^{16}$, Antonio Granell ${ }^{17}$, Gabriel Clapers $^{18}$, Rodrigo Eanes ${ }^{19}$ y, de nuevo, Antonio Granel ${ }^{20}$

4. En este momento - primer semestre de 1465—, Tomás Sola ejecuta gastos con dinero procedente de las rentas del Arcedianato de la Mar, y ya no con dinero procedente de los bienes eclesiásticos confiscados (como el rey le dice expresamente en muchas de sus órdenes de pago). Son 3.580

Sant Celoni, canónigo y presidente del monasterio de S. Pedro de Rodas, es citado por Gaspar Vilana para comparecer, en el plazo de 4 dias, en la Audiencia Real para tratar de la queja presentada por Tomás Sola, administrador de las rentas eclesiásticas confiscadas (íd., fol. $67 r-67 \mathrm{~V}$ ); jdénticas djficultades se presentan a A stonio Granell, procurador de los beneficios eclesiásticos confiscados, por lo que el rey protesta el 22 de abril junto del cabildo de la catedral de Barcelona (id., fol. 58v) y del Portantveus (id. fol. 58rII).

is Reg. 22, fol. 202 vII (13 abr. 1465): el rey promete restituir a Pedro Exarrat, «pabordes de Castellón, las 55 libras barcelonesas que él entregó, caso que se pruebe que él nada debe a la tesorería real de los bienes de eclesiásticos rebeldes, que él administraba.

16 Reg. 22, fol. 97v (19 jun. 1465): el rey encarga a Bernardo Planella, presbitero beneficiado de la iglesia parroquial de Castellón de Ampurias, secuestrar los bienes eclesiásticos de las localidades sometidas a la obediencia del obispado de Gerona; después, indica cómo debe administrar dichos bienes.

${ }^{17}$ Reg. 22, fol. 117 I (6 jun. 1465): el monarca encarga al presbítero Antonio Granell que, de los fondos de los beneficios y dignidades eclesiásticas de rebeldes que el administra, no entregue ninguna cantidad sin autorización del rey ( $\mathrm{cf}$. cartas citadas en la nota 14; es Antonio Granell quien recibe la carta citada en el asiento [87]).

18 Reg. 22, fol. 127r-127v (20 jul. 1465): el monarca ordena a Antonio Granell y Juan Ledó, presbiteros, colectores de las rentas de beneficios y dignidades eclesiásticas de rebeldes. que entreguen los fondos que poseian a Gabriel Clapers, maestro en Teología, comensal de la catedral de Tortosa, receptor general de dichas rentas (confirmado por carta del 18 de diciembre de ese año; íd., fol. 177v). C. reg. 24, fol. $130 \mathrm{vII}$ (23 dic. 1465), donde Gabriel Clapers recibe orden de, con dichas rentas, pagar 100 florines a quien es debido por las obras realizadas en el Palacio Real (cf. nota 45).

19 Reg. 61 , fol. 15r-15v ( 3 nov. 1465): el monarca escribe a los capitanes del castillo y villa de Campreal (La Bisbal), comunicándoles que Rodrigo Eanes pasará a recibir los dineros de los rebeldes de la Mensa Episcopal de Castellreal, Cruilles, S. Sadurnf, Corsá, Rupiá y UIIa.

20 Cf. este conjunto de cartas del 30 de enero de 1466: reg. 22, fol. 182vI y II (Antonio Granell recibe orden de abrir una investigación sobre los bienes del difunto sacerdote Pedro Cervia, que murió sin hacer testamento; el monarca piensa que dichos bienes le pertenecen); reg. 24, fol. 137vll (Antonio Granell recibe orden de entregar a Juan Vicente 2.122,5 sueldos que tiene en su poder, wles quals haveu reebudes de mossen Joan Fexes, prevere, qui les tenia proceides de la heretat de mossen Pere Cervia, prevere, mort ab intestat, la distribucio de la qual se pertany a la mensa episcopal $n$ ); reg. 24, fol. $137 \mathrm{vI}$ (el monarca declara haber recibido los 2,122,5 sucldos citados en la carta anterior, y declara que los destinará a la usustentacio de la vila e castell de Citgess). 
sueldos que el capellán recibe ${ }^{21}$, cantidad suficiente para cumplir lo que le es ordenado por el monarca ${ }^{z z}$.

Podemos, por lo tanto, añadir que el Condestable intenta, entre finales de 1464 y principios de 1465 , dar a la capilla real condiciones para que ésta pase a disponer de autonomía financiera relativa a la tesorería real (circunstancia que no ocurría anteriormente, como ya se indicó). El próposito real es el de sufragar dichos gastos con las rentas de los bienes eclesiásticos confiscados; no lo logra, por lo que es obligado a diversificar la utilización de las referidas rentas por distintos nombres sin gran entidad entre los funcionarios de la administración, y a mantener los gastos de Tomás Sola con la única renta eclesiástica confiscada que le posibilita fondos regulares: los fondos del Arcedianato de la Mar.

5. Siendo así, consideremos ahora el caso específico de estos fondos. En los primeros meses de su gobierno, el Condestable no interviene en tales rentas $^{23}$, pero, al poco tiempo, ya encontramos manifestaciones de su interés, al ordenar la entrega de dos cantidades procedentes del Arcedianato de la Mar a Francisco Torro, secretario real ${ }^{24}$, y al portugués Juan de Castelo $\mathrm{Branco}^{25}$. Pensamos que dichos pagos no se llegan a efectuar, como igualmente no se ejecutará la orden de entregar al capellán Juan Martínez distintos emolumentos del Arcedianato de la Mar; concretamente, este último dinero parece que se destinaba a pagar el ofertorio desde el primer día de mayo anterior hasta finales de octubre, así como el de los días 1 y 2 de noviembre (la carta real es del 28 de octubre) ${ }^{20}$. Por ese incumplimiento, el 11 de diciembre, el lugarteniente del tesorero, Fernando Eanes, hace una transferencia aislada hacia las manos de Juan Martínez, destinada a cubrir gastos retrasados, entre los cuales el ya citado ofertorio correspondiente a los meses de mayo a noviembre ${ }^{27}$. Con este fracaso - al cual hay que añadir el ulterior con Tomás Sola, ya referido - muere así el proyecto de don

21 Véase cuadro de la pág. 22.

22 Asientos [50] a [60], Como se comprueba, hay una pequeña diferencia de 10 sueldos respecto a la cantidad ingresada del $\mathrm{A}$. de la Mar [44], diferencia ya apuntada en las pags. 22 y 34.

23 El 8 de junio de 1464, escribe al cabildo y canónigos de la catedral de Barcelona, comunicándoles que wha donat special carrech al Archiaca Colom del Archiaconat de la Mar pregant los nol empachen en allo nel perturbenw (reg, 2I, fol. 73r).

${ }^{24}$ Francisco Colom es nombrado, el 1 de septiembre de 1464, administrador del Arcedianato de la Mar y de su anejo de S. Vicente (reg. 21, fol. 153r-153v). Días antes ( 13 de agasto), Colom recibe orden de entregar a F. Torro 130 libras procedentes de las rentas del Areedianato de la Mar, «les quals reebra per nostra parts (id., fol. $113 \mathrm{r}-113 \mathrm{v}$ ).

${ }^{25} \mathrm{Reg}$. 23, fol. 102rll (6 sep. 1464): F Colom entrega a J. Castelo Branco 100 libras procedentes de las mismas rentas.

26 Reg. 21, fol. 183 r.

27 Asiento [17]. 
Pedro de dotar a la capellanía real de fondos propios que le garantizasen la autonomía financiera.

Es probable que, en Barcelona, las autoridades religiosas advertieran perfectamente el plan del monarca. Por eso se explican las dificultades que encuentra Tomás Sola para cobrar las rentas de los eclesiásticos rebeldes, o la actitud del vicario general de Barcelona y del cabildo de la catedral que impiden la recepción de los emolumentos del Arcedianato de la Mar por parte del arcediano Pedro Lladó, como quería el rey ${ }^{28}$. Éste no desiste y, todavía antes de finales de 1464, reclama dichas rentas argumentando que éstas le pertenecen porque han sido propiedad de eclesiásticos rebeldes, de acuerdo con lo estipulado con ocasión de su venida a Cataluña ${ }^{29}$. Y, si así lo pensaba, así lo cumplió: siguiendo su programa, en el inicio de 1465, el monarca decide intervenir directamente en la administración de esos fondos; la decisión real es comunicada el 29 de enero al cabildo de la catedral y a Juan Ledó, presbítero beneficiado de Santa María del Mar y administrador de dichas rentas ${ }^{30}$.

Esta decisión presenta un doble componente: de una parte, es un elemento más en la política real de confiscar los bienes pertenecientes tanto a personalidades como a instituciones adversas a su causa; de otra parte, se integra en la ya referida orientación del Condestable de independizar la capilla real de los fondos de la tesorería, y es en este segundo aspecto que la consideramos en el presente estudio.

6. La fórmula administrativa que el Condestable elige para utilizar dichas rentas contempla su especificidad; porque no se trata de unos bienes confiscados aisladamente, sino de un organismo con medios propios; y el control directo por parte de la administración no parece ser la fórmula más adecuada. Así, se utiliza la solución del alquiler, usual en la época.

Sin embargo, no fue fácil llevar a cabo este proyecto ${ }^{31}$; solamente el 10 de febrero de 1466 - meses después- se efectúa el alquiler en cuestión ${ }^{32}$.

28 Archivo Capitular de Barcelona, «Cartas Reales», nuim. 109 (16 nov. 1464) y núm. 108 (10 dic. 1464), sumariadas en el catálogo de dicho fondo publicado por J. OLIVERAS CAMINAL. (Barcelona, 1964), núm. 526 y 525.

${ }^{29}$ Reg. 21, fol. 194v (16 nov. 1464).

${ }^{30} \mathrm{Reg} .22$, fol. $64 \mathrm{r}-65 \mathrm{v}$.

${ }^{3}$ En una carta del rey al canónigo de la catedral de Barcelona, Caplana, le pide que entregue al mercader Arnaldo Massana las rentas del Arcedianato de la Mar, pues este mercader las ha alquilado por un año a partir del primero de abril (reg. 22, fol. 76v-77r). Cf. fd., fol. 77rll, dande el monarea escribe a Nicolás Bernat solicitándole una conia del ustal contrato de alquiler del Arcedianato de la Mar, a fin de redactar uno igual para A. Massana.

${ }^{32}$ Reg. 61. fol. 35r-36r, publicado por J.E. MARTINEZ FERRANDo,Pene de Portugal, rei dels catalans, vist a través dels registres de la seva cancelleria, Barcelona, Institut dEstudis Catalans, 1936, doc. p. 238-239. En esta carta se declara que dicho alquiler se debe a la rebelión de Nicolás Pujada, su anterior poseedor, y se especifica la cantidad a cobrar ( 600 libras). 
Entre enero de 1465 y febrero de 1466 (mientras dicho alquiler no se formalizaba), el Condestable no puede hacer otra cosa sino gestionar el dinero indirectamente: Juan Ledó continúa al frente de la administración, y don Pedro, caso a caso, solicita al citado Ledó la entrega de dinero a distintas personalidades ${ }^{33}$.

En este sentido, los cuadernos de cuentas del Arcedianato registran los gastos que aparecen en el cuadro 4 del apéndice.

Como a partir del primero de abril de 1465 , el alquiler de las rentas ya se encontraba - teóricamente- resuelto, los gastos pasan a ser por orden directa del rey. Así, entre el primero de abril y el 30 de noviembre de 1465 , tenemos los gastos que se detallan en el cuadro 5 del apéndice ${ }^{34}$.

Finalmente, en diciembre de 1465 ya está cercana la firma del alquiler ${ }^{35}$, que se efectuará en febrero siguiente ${ }^{36}$. Ahora, los pagos realizados por Juan Ledó se sitúan en un ámbito distinto; de acuerdo con lo estipulado en el contrato de alquiler, el monarca recibe 600 libras, pasando la administración a ser responsabilidad de dicho mercader. Así, a lo largo del año de 1466, las cuentas de Juan Ledó registran la salida de 5.580 sueldos, siempre por indicación de Arnaldo Massana ${ }^{37}$ (cuadro 6).

Como sabemos, el Condestable don Pedro muere a finales del mes de junio de 1466. Posteriormente, la administración del Arcedianato de la Mar cambia de persona ${ }^{38}$.

7. Pensamos que ya es posible, desde aquel momento, llegar a algunas conclusiones relativas al tema que nos ocupa, aunque se imponga esperar el estudio de conjunto de las finanzas reales para poder hablar de conclusiones con carácter más definitivo.

13 De esto son reflejo los cuadernos de cuentas existentes en el Archivo de $M$. Racional (ACA. MR, nüm. 2837, cuaderno 1-2-3). Cf, reg, 24, fol, 70vI (6 jul, 1465), donde el monarea ordena a Juan Ledó que de cualesquiera rentas del Areedianato, «les quals per nos colligui e reebeu, no doneu alguna quantitat a alguna persona, si donchs per nos ab nostra letra de nostra ma signada nous era manat, car altrament nous sere mes en compten.

34 Estas cifras están fundamentadas en MR, núm. 2837 (cit. en la nota 33), cuaderno 2, fol. $24 r$ y $28 \mathrm{r}$.

35 El 6 de diciembre, don Pedro escribe a Nicolás Bernat, pidiéndole teque se informe quant valen en aquest temps les rendes del Archiachonat de la Mar» (reg. 22, fol, 172r).

36 Véase nota 32.

37 Esta cifra está fundamentada en MR, núm. 2837 (cit. en la nota 33), cuaderno 3, fol. 22 r.

38 F. Sotsona Cument, «Aspectos de la dominación angevina en Cataluña (1466-1472): la participación italiana y francesa en la revolución contra Juan II de Aragón, "J. Zurita", 14-15, $1963 v$ p. 33, citando ACA, Cartas reales de Juan II, caja 3, núm. 6 y Cancilleria, Intrusas, reg. 57 , fol. 50,62 y 80 , escribe que Boffillo de Judice fue encargado en 1467 de recibir de los manumisores del Condestable las cantidades procedentes de la Mensa Episcopal de Barcelona y del Arcedianato de la Mar. En MR, núm. 2837 (citado en la nota 33), cuaderno 3. fol. Ir, se diee que con la muerte de Don Pedro la administración del A. de la Mar cambió de persona. 
En primer lugar, las rentas eclesiásticas, a lo largo de todo el gobierno del Condestable de Portugal, cuando eran propiedad de rebeldes y una vez confiscadas, han sido utilizadas al servicio del rey, y con frecuencia dadas a partidarios suyos. Tanto en la justificación legal para la confiscación como en el destino que les es dado por don Pedro, estas rentas no presentan ninguna diferencia respecto a la general confiscación de bienes de rebeldes practicada por el monarca ${ }^{39}$.

En segundo lugar, se comprueba cómo dichas rentas han tenido un significativo papel en el conjunto de las finanzas reales, como es el caso de los fondos del Arcedianato de la Mar, estudiados anteriormente, o ciertos fondos pertenecientes «a la fabrica de la Seu de Gerona», en cuyo manejo intervienen el capellán Bernardo Planella y el funcionario de la tesorería Nicolás Company ${ }^{40}$.

En tercer lugar, podemos, por lo tanto, intentar determinar el valor del conjunto de las rentas eclesiásticas manejadas por el Condestable don Pedro. Si es verdad que, por todas estas razones, no es posible hablar de un presupuesto de gastos de la Capilla Real, sin embargo cabe dibujar su valor global en función de dos tipos de valores parciales: de una parte, las cantidades que pasan por las manos de los capellanes, incluyendo los sueldos que tales personas reciben, así como las cantidades que proceden de fondos eclesiásticos; de otra parte, las cantidades que, aunque no sean tramitadas por capellanes o no sean de procedencia eclesiástica, corresponden, sin embargo, a gastos propios de una capilla. Obtenemos así el cuadro 8 de conjunto.

Obtenemos así un valor total de 51.816 sueldos y 5 dineros, como resultante de la suma de las cantidades que corresponden al dinero que pasa por las manos de los capellanes y al dinero que corresponde a gastos propios de una capilla real. Evidentemente se trata de una cantidad aproximada, muy probablemente como valor mínimo, ya que importa añadir los pagos en telas y los dineros confiscados a eclesiásticos rebeldes, difícilmente contabilizables ${ }^{41}$. Podemos por lo tanto apuntar un presupuesto de gastos de la capilla superior a los 50.000 sueldos.

39 La lista general de bienes confiseados a rebeldes será publicada en otro estudio.

40 El 16 de diciembre de 1465 , el funcionario de la tesoreria Nicolás Company recibe de las manos del capellán Bernardo Planella, del citado fondo de la catedral de Gerona, 1.445 sueldos y 9 dineros (reg. 24, fol. 128rI y II). De este dinero, al día siguiente, Nicolás Company recibe orden de entregar 1.320 sueldos (probablemente es todo cuanto recibió) a Berenguer Granelh (id., fol. 130vl). Conocemos con exactitud el destino dado por el monarca a dichos 1.320 sueldos, por las órdenes reales dirigidas a este Berenguer Granell en el mismo mes de diciembre (cuadro 7 del apéndice).

41 Por ejemplo, el 21 de junio de 1465, el rey manda a Tomás Sola que de las rentas kquis cullen en lo loch de Ulla, les quals fossen de qualsevol ecclesiastichs [rebeldes] del dit loch de Ulla... respongau ara e daquiavant cascun any e tant con a nos plaura al amat capellan de nostra capella mossen Berthomeu Peyros (reg. 24, fol. 58rIV). Véanse también los pagos 
En cuarto lugar, llegados a estas cifras, sería interesante comparar su valor con otras cifras de las finanzas del Condestable, con el propósito de mejor determinar su peso real en el conjunto de la administración financiera de don Pedro. Por supuesto, reconocemos el enorme grado de provisionalidad que presentan estos valores, por lo cual solamente les atribuimos un significado indicativo. En este sentido, si aceptamos que la renta ordinaria realmente cobrada por los funcionarios de la tesorería (Guillermo y Luis Setanti, Fernando Eanes) entre enero de 1464 y junio de 1466 corresponde a cerca de 300.000 sueldos $^{42}$, o si aceptamos que la cantidad realmente cobrada del impuesto especial creado por el Condestable a partir de mediados de 1465 corresponde a cerca de 50.000 sueldos $^{43}$ — para citar apenas dos ejemplos no estaremos muy lejos de la verdad al decir que las rentas eclesiásticas y los fondos de la capilla real, en su conjunto, representaron, para las finanzas del monarca, tanto como el impuesto especial cobrado entre mediados de 1465 y mediados de 1466 o cerca del $17 \%$ de la renta ordinaria a lo largo de los tres años y medio del gobierno de don Pedro. Desde este punto de vista, estas rentas se presentan dotadas de un significativo valor económico, circunstancia que justifica plenamente su utilización dentro de un abanico muy amplio de gastos.

Siendo así, se impone, en último lugar, determinar en qué fue utilizado el dinero que en principio era de la capilla (cuadro 9).

Como se comprueba, hay un claro desplazamiento del dinero hacia gastos exteriores a la capilla. Por ejemplo, y referiéndonos concretamente a la cantidades que ingresan en manos de los capellanes (que serían las rentas específicas de la capilla real), en un total de 24.598 sueldos, encontramos la siguiente disparidad: en lo relativo a la procedencia del dinero, el $73 \%$ corresponde a rentas eclesiásticas y el $26 \%$ corresponde a fondos de la tesorería ${ }^{44}$; mientras en lo relativo al gasto del mismo dinero, el $78 \%$ corresponde a gastos civiles de la casa real y el $22 \%$ corresponde a gastos de la capilla y a limosnas ${ }^{45}$. O sea, dicho desplazamiento corresponde a cerca de la mitad del total del presupuesto de la Capilla Real. Este hecho, a su vez, se confirma más ampliamente al contabilizar el conjunto de los

siguientes en telas: A pobreza (estudio citado en la nota 1), apéndice A, núm. 11, 27, 30, 32, 43 (publicado en id. p. 437), 64, 67, 70, reg. 23, fol. 50vIII yMR 2489 , fol. $98 \mathrm{vII}$ y $116 \mathrm{vIII}$ (11 may. 1464); reg. 23, fol. 75 rII y 76vIII (31 jul. 1464); reg. 23, fol. 97vI (31 ago. 1464); reg. 23 , fol. 28 vir (17 abr. 1464), etc. En cuanto a Ios dineros confiscados, véanse fas notas 14 y 5 .

42 o Condestavel D. Pedro de Portugal (op. cit. en la nota 1), cuadro 7, p. 227.

43 fd. p. 281.

44 Véase cuadro de la p. 27. Incluimos en las rentas eclesiásticas, los 12.968+4.900: en los fondos de la tesorería, los 6.459. El 1\% que falta corresponde a los 271 . Texto de Pie

45 Véase cuadro de la p. 29. 
gastos correspondientes a los 51.816 sueldos y 5 dineros, ya referidos (cuadro 10).

Llegados al final de este estudio de las rentas eclesiásticas y de los fondos de la capilla real durante el gobierno del Condestable don Pedro como rey intruso de Aragón (desde enero de 1464 a junio de 1466), podemos decir, en suma, que dicho estudio nos permitió analizar con detalle el valor, procedencia, destino y administración de tales fondos. Pero nos permitió también comprobar, por otros caminos, lo que ya escribimos al respecto de la política monetaria del monarca: nos encontramos ante una praxis administrativa que persigue la obtención y transferencia de fondos desde áreas donde tales fondos eran controlados por instituciones ajenas al rey, hacia cauces donde la utilización del dinero no era controlada por esas instituciones $^{46}$. Se va perfilando, de esta forma, la organización, a mediados del siglo XV, de una administración financiera pautada por exigencias muy particulares derivadas de las circunstancias bélicas en las que vivía entonces el Principado de Cataluña; dicho en otras palabras, se va perfilando lo que podría llamarse una administración financiera de guerra, en el presente caso estudiada a partir del dominio de las rentas de la capilla real.

460 Condestável D. Pedro de Portugal (op, cit. en la nota 1), p. 253. 


\section{APÉNDICE}

\section{CUADRO 1}

\begin{tabular}{|c|c|c|c|}
\hline Fecha & Destinatario que recibe el dinero & Sueldos & Fuente \\
\hline $\begin{array}{l}1464 \text {-sep-3 } \\
1465 \text {-jul-23 }\end{array}$ & $\begin{array}{l}\text { Tesorería real (Fernando Eanes) } \\
\text { F. Valente, capitán de Vilarredo- } \\
\text { na, como ayuda para dicha villa } \\
\text { y castillo. }\end{array}$ & 4.000 & $\begin{array}{l}\text { vd. nota } 9 \\
\text { reg, } 24, \text { fol. } 78 \mathrm{r}\end{array}$ \\
\hline 1465 -ago-14 & $\begin{array}{l}\text { A de Obidos, para pagar el } \\
\text { sueldo de los soldados }\end{array}$ & 3,000 & reg. 24, fol. $87 \mathrm{rI}$ \\
\hline 1466-mar-21 & Juan de Silva & 2.800 & reg. 27 , fol. $61 \mathrm{r}$ \\
\hline $1466-\mathrm{mar}-23$ & Juan de San Juan & 2.618 & $\begin{array}{l}\text { reg. } 24, \text { fol. } 218 \mathrm{r}- \\
218 \mathrm{v}\end{array}$ \\
\hline & Total & 12.968 & \\
\hline
\end{tabular}

\section{CUADRO 2}

\section{CAPEII ÁN JUAN MARTINEZ}

\begin{tabular}{|l|l|r|r|}
\hline \multirow{2}{*}{$\begin{array}{l}\text { Dinero recibido de la mano } \\
\text { de alguno de los tesoreros }\end{array}$} & Guillermo Setanti & \multicolumn{1}{|c|}{260} \\
\cline { 2 - 3 } & Luis Setanti & 780 & \multirow{2}{*}{$4.0519 \mathrm{~d}$} \\
\cline { 2 - 3 } & Fernando Eanes & $3.0119 \mathrm{~d}$ & \\
\hline \multirow{2}{*}{$\begin{array}{l}\text { Dinero recibido de otras } \\
\text { procedencias }\end{array}$} & J. Castelo Branco & $3335 \mathrm{~d}$ & \multirow{2}{*}{$6095 \mathrm{~d}$} \\
\cline { 2 - 3 } & B. Venrell & 276 & \\
\hline & diversos & - & \\
\hline & Total & & \\
\hline
\end{tabular}

\section{CAPELLÁN TOMÁs SOLA}

\begin{tabular}{|l|l|c|}
\hline $\begin{array}{l}\text { Dinero recibido de la mano de } \\
\text { algún tesorero }\end{array}$ & Fernando Eanes & 2.057 10d \\
\hline $\begin{array}{l}\text { Dinero recibido de otras proce- } \\
\text { dencias }\end{array}$ & Arcedianato de la Mar & 3.580 \\
\hline \multicolumn{2}{|c|}{ Total } & $5.63710 \mathrm{~d}$ \\
\hline
\end{tabular}




\section{CUADRO 3}

\begin{tabular}{|l|r|c|}
\hline \multicolumn{1}{|c|}{ Tipo de gastos } & Cantidad & \% \\
\hline Caridad y pobres & 1.143 9d & 35,5 \\
\hline Ofertas y oferta mensual & 351 6d & 10,9 \\
\hline Misas extraordinarias & 39 & 1,2 \\
\hline Velas & $25711 \mathrm{~d}$ & 8 \\
\hline Cosas para la capilla real & 1.170 5d & 36,3 \\
\hline Caballos & 260 & 8.1 \\
\hline Total & 3.222 7d & 100 \\
\hline
\end{tabular}

\section{CUADRO 4}

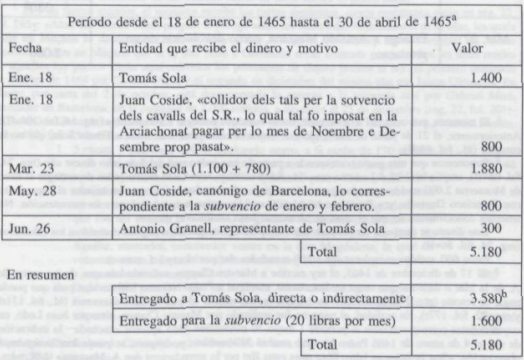

"Estas cifras están fundamentadas en MR, núm. 2837 (cit. en la nota 33), cuaderno 1, fol. 21 r.

b La justificación de esta entrega se encuentra en el diploma del 29 de septembre anterior citado en la nota 13. 


\section{CUADRO 5}

\begin{tabular}{|l|l|c|}
\hline \multicolumn{2}{|c|}{ «Dades en la Taula de la ciutat» } & Valor \\
\hline Oct. 4 & $\begin{array}{l}\text { Entregue al presbítero Juan Bevages, eper vestirse e } \\
\text { per altres respectess. }\end{array}$ & $500^{c}$ \\
\hline Nov. 17 & $\begin{array}{l}\text { Entregue al maestro Francisco Vidal. } \\
\text { Nov. 17 }\end{array}$ Entregue a Bernardo Stopinya. & $260^{\mathrm{d}}$ \\
\hline \multicolumn{1}{|c|}{ Dado en numerario directamente } & 340 \\
\hline Ago. 15 & Entregue a Alfonso de Óbidos. & $2.000^{\mathrm{c}}$ \\
\hline Oct. 7 & Entregue a Juan Bevages. & $600^{f}$ \\
\hline
\end{tabular}

\section{CUADRO 6}

\begin{tabular}{|l|l|c|}
\hline Ene. 5 & Entrega a Pedro Navarro para pagar su rescate. & $380^{\mathrm{g}}$ \\
\hline Mar. 27 & $\begin{array}{l}\text { Entrega a Amaldo Massana, como devolución de un } \\
\text { préstamo. }\end{array}$ & $2.000^{\mathrm{h}}$ \\
\hline
\end{tabular}

E. El monarca, por carta del 4 de octubre, había mandado entregar 1.100 sueldos (reg. 14, fol. 104vII). Anteriormente, el 21 de junio de 1465, idéntica orden del día había sido dada a Tomis Sola, que no la curnplió (id., fol. 60rII).

Suponemos que este gasto corresponde a parte de una orden real del 5 de julio de ese año (reg. 24. fol. 66vII), ampliada el 28 del mismo mes (fd., fol. 81 y-82r): Jaan Ledó recibe orden de entregar al abad de Monserrat 2.000 sueldos para los gastos de sa viaje a Roma, donde ira como embajador al Papa, junto con Francisco Dezvalls, y a Francisco Vidal 600 sueldos como menced real para su manutención. No tenemos conocimiento de que el abed de Monserrat haya recibido el dinero,

- Este dinero se destina a ser prestado a los điputados para que éstos paguen el sueldo a los caballeros (reg. 24, fol. 86vII).

Estos 600 sueldos completan los 1.100 mandados dar por el rey (cf. nota c).

12 El 17 de diciembre de 1465, el rey escribe a Maestre Clapers, solicitándole que, de las rentas de A. de la Mar o de otras que tenga en sus manos, entregue a Pedro Navarro 880 sueldos para que pueda pagar su reseate (reg. 24, fol. 128vII); esta orden es renovada el 18 y el 30 del mismo mes (id., fol. 131rl y reg. 22, fol. 177r). En realidad, el pago no fue realizado por Maestre Clapers, sino por Juan Ledó, en cuyas cuentas correspondientes al período 1 mayo-30 noviembre 1465 aparece - tachada- la indieación de que el 4 de enero de 1466 Pedro Navarro recibió 380 sueldos; $y$, después, se puede leer la siguiente observación: «Son posades en laltro libre ques estat ffet per lo arrendament den A. Massana* (MR, núm. 2837, cuaderno 2, fol. 24r).

b' Esta entrega debe estar relacionada con una carta (fechada del 27 mar. 1466) dirigida a Amaldo Massana, mercader de Barcelona, en la cual el monarea se declara deudor de 2.000 sueldos a Miguel Sayol, entonces fallecido, desde hace más de un año, por lo cual pide al dicho Massana que, de las rentas del A. de la Mar, pague la cantidad indicada a la viuda (reg. 24, fol. 153rI). En efecto, el cítado Miguel Sayol había prestado 2.000 sueldos a Doo Podro el $28 \mathrm{sep}$. 1464 (reg. 22, fol. 201r). No sabemos cuál es el destino dado a ese dinero. Es posible que haya servido para pagar al mismo Miguel Sayol un préstamo 
CUADRO 6 (Continuación)

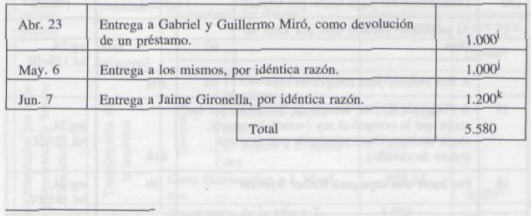

anterior, del mes de marzo de 1464, por el valor de 1.300 sueldos, el cual fue recibido por el lugarteniente del tesorero Fernando Eanes (ACA, MR, núm. 2489, fol. 2riI). Sin embargo, es plausible otra interpretación. El citado préstamo del 28 sep. 1464 fue realizado por 3 personas (Antonio Vinyes, notario de Barcelona, que entregó 1.300 sueldos, Pedro Pons, mercader de Barcelona, que entregó 2.000 sueldos: y Miguel Sayol, sbavilo aquarums de Barcelona, que entreg6 2.000 sueldos; reg. 22, fol. 20lr, ya citado), en un total de 5.300 sueidos. Quiere esto decir que, muy probablemente, do este total una parte se dedico a la devolución del préstamo. ¿Cual? Es muy dificil, en este momento, contestar con exactitud; sólo un estudio de conjunto, detallado, de las cuentas reales de estos meses lo podrí decir.

'El 9 de marzo anterior, el monarca escribe las cartas siguientes, cuyos resúmenes están en reg. 22, fol. 195v: «Altra an Gabriel Miro, pregant lo prenga sobre les rendes del Archiachonat de la Mar, les quals culle ea Maçana lo deute que li deu lo Senyor Rey e daço fi sera servey. Altra semblant an Jaume Geronella, altra an Maçana que si lo dits Miro e Geronella seran contents pendre sobre les dites rendes de aquelles loy pach. $\nsim$ Están aquí referidos los préstamos de dinero hechos al rey: el primero realizado en octubre de 1464 por Gabriel Miró, y el segundo en diciembre del mismo año por Jaime Gironella. En efecto, por carta del 2 de octubre, estí documentada la entrega a la tesoreria real por Gabriel Miro, mercader de Barcelona, de la cantidad de 2.000 sueldos, a devolver el 25 de diciembre (reg, 22, fol. 201r201 v; en los libros de la Generalidad la entrega aparece con fecha del 11 de octubre, Gen. Manual común, núm. 482, fol. $75 \mathrm{v}$ ). Esta cartidad corresponde a las partidas siguientes:

L. 5 canas, 5 palmos y $1 / 4$ de terciopelo negro, a la razán de 130 sueldos cada cana, entregados a Fernando Eanes para servicio de la corte

2. uper integra satisfaccio de aquelles quaranta quatre lliures, relaxada e remesa a nos liberament, la restant quantitat en les quales vos ereu creedor eus ereu stades assignades en la cambrada de la Magdalena dor que fou del Princep don Karles, de gloriosa recordacio lhace referencia a Carlos de Vianal, la qual era en poder del feel nostre en Joan de Aguilar, mercador, concreedor vostre en la dita Magdalena, la qual de voluntat vostra e de tots los altres credors es pervenguda ea oostre poder e en mans nostres assignada.

3. Depositadas por G. Miró a la Taula de Barcelona, en nombre de Femando Eanes, que lo recibe en sa calidad de lugarteniente de la tesoreria.

El préstamo hecho por J. Gironella está indicado en la nota 49.

Véase nota anterior.

k Pensamos que esta cantidad de 1.200 sueldos se destina a devolver un préstamo hecho por $\mathbf{J}$. Gironella (cf. cartas del 9 mar. 1466, citadas en la nota i). Fl único préstamo hecho al rey por dicho Gironella de que tenemos conocimiento es el que está registrado con fecha del 1 de diciembre de 1464 en el valor de 4.764 sueldos (reg, 22, fol. 202r); según informa el monarca, esta cantidad corresponde a distintos paños que le fueron comprados por el lugarteniente de la tesorería Fernando Eanes, con la intervención de Alfonso de Óbidos. Si es éste el préstamo en causa, no sabemos cuándo se han devuelto los sueldos que faltan para completar el total, ni si tal devolución se llegó ar realizar. 


\section{CUADRO 7}

\begin{tabular}{|c|c|c|c|c|}
\hline Día & Destinatario del pago hecho por Granell & \multicolumn{2}{|c|}{ Cantidad } & Fuente \\
\hline \multirow[t]{2}{*}{17} & $\begin{array}{l}\text { Al presbitero Mossèn Gui, por amor de } \\
\text { Dios }\end{array}$ & 60 & rent & \multirow{2}{*}{$\begin{array}{l}\text { reg. } 24 \\
\text { fol. } 128 \text { vIII }\end{array}$} \\
\hline & A Rui Pereira, para compra de ropa & 44 & 104 & \\
\hline 18 & \multicolumn{2}{|c|}{$\begin{array}{l}\text { A Francisco Rovira, armero de Barcelona por las } \\
\text { cosas que le compró el rey (acinch bicoquets, } \\
\text { cinch baveres, cinch perells de cuxots e una } \\
\text { testera de cavall») }\end{array}$} & 616 & $\begin{array}{l}\text { reg. } 24, \\
\text { fol.129rII }\end{array}$ \\
\hline 18 & \multicolumn{2}{|l|}{ Por hacer una capa para Rafacl Squerdo } & 30 & $\begin{array}{l}\text { reg. } 24, \\
\text { fol. } 193 \text { rIV }\end{array}$ \\
\hline \multirow{5}{*}{20} & $\begin{array}{l}\text { Por «mitja carrega de vinagre e onze } \\
\text { cortons doli per obs de la sisterna del } \\
\text { Castell de Centelles ana Berthomena } \\
\text { Cendras }\end{array}$ & 19 & 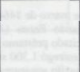 & 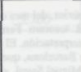 \\
\hline & $\begin{array}{l}\text { «An Gabriel Busquets, per xbiiij carre- } \\
\text { gues de calç a obs del dit castell, }\end{array}$ & 19 & 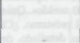 & 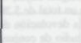 \\
\hline & $\begin{array}{l}\text { «A Mestre Joan Bo, guanter, per nou } \\
\text { pells de cabrit per forrar un nostre } \\
\text { gipos }\end{array}$ & 13 & 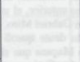 & $\begin{array}{l}\text { reg. } 24 \text {, } \\
\text { fol.131v }\end{array}$ \\
\hline & $\begin{array}{l}\text { ¿Per deu Ifiures de coure qui fonch } \\
\text { liurat a Mestre Galter, bombarders }\end{array}$ & 7,5 & & $132 r$ \\
\hline & $\begin{array}{l}\text { «er la sepultura de un servidor de } \\
\text { Tristany de Silva, lo qual es mort en la } \\
\text { present ciutato }\end{array}$ & 30 & 88,5 & 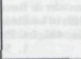 \\
\hline 20 & \multicolumn{2}{|l|}{ Transferencia al funcionario Diego Pratas } & 400 & $\begin{array}{l}\text { reg. } 24, \text { fol.1- } \\
32 \text { rI }\end{array}$ \\
\hline 22 & \multicolumn{2}{|l|}{ A Ramón Campdepos, sfeel manescal» real } & 60 & $\begin{array}{l}\text { reg. } 24,- \\
\text { fol. } 194 \mathrm{rl}\end{array}$ \\
\hline \multirow[t]{3}{*}{24} & $\begin{array}{l}\text { Per «un perell de portadores que han a } \\
\text { servir per la obra del castell de Cente- } \\
\text { lles». }\end{array}$ & 9 & \multirow{3}{*}{22,5} & \multirow{3}{*}{$\begin{array}{l}\text { reg. } 24 \\
\text { fol. } 13 \text { ivil }\end{array}$} \\
\hline & $\begin{array}{l}\text { Per equatre corteres de calç e dos ca- } \\
\text { nastesw }\end{array}$ & 7,5 & & \\
\hline & $\begin{array}{l}\text { Per el "port de una carrega en que } \\
\text { havia antorxes e altres coses de Baree- } \\
\text { lona en la present ciutat de Vich» }\end{array}$ & 6 & & \\
\hline
\end{tabular}

a Como se comprueba, hay una diferencia de un sueldo entre la cantidad que recibe Berenguer Granell y la suma de los gastos que le son ordenados por el rey. 


\section{CUADRO 8}

\begin{tabular}{|c|c|c|c|c|c|}
\hline \multirow{2}{*}{$\begin{array}{l}\text { Tipo de } \\
\text { proce- } \\
\text { dencia }\end{array}$} & \multirow{2}{*}{$\begin{array}{l}\text { Proceden- } \\
\text { cia }\end{array}$} & \multirow{2}{*}{\multicolumn{2}{|c|}{ Destinatario del dinero }} & \multicolumn{2}{|c|}{ Valor } \\
\hline & & & & Valor parcial & Valor total \\
\hline \multirow{9}{*}{ 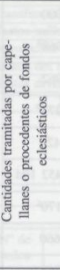 } & $\begin{array}{l}\text { Mesa } \\
\text { Episcopal }\end{array}$ & & & & $12.968^{\mathrm{a}}$ \\
\hline & \multirow{4}{*}{ 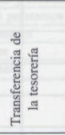 } & \multirow{3}{*}{ 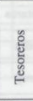 } & $\begin{array}{l}\text { F. Eanes a Juan } \\
\text { Martinez }\end{array}$ & $3.0119 \mathrm{~d}$ & \\
\hline & & & $\begin{array}{l}\text { F. Eanes a Tomás } \\
\text { Sola }\end{array}$ & $2.05710 \mathrm{~d}$ & \\
\hline & & & $\begin{array}{l}\text { L. Setanti a J. Marti- } \\
\text { nez }\end{array}$ & 780 & \\
\hline & & \multicolumn{2}{|c|}{$\begin{array}{l}\text { Otros funcionarios a J. Martí- } \\
\text { nez }\end{array}$} & $6095 d$ & $6.459^{b}$ \\
\hline & & \multicolumn{2}{|c|}{$\begin{array}{l}\text { Arcedianato de la Mar a T. } \\
\text { Sola }\end{array}$} & 3.580 & \multirow[t]{2}{*}{$4.900^{c}$} \\
\hline & & \multicolumn{2}{|c|}{$\begin{array}{l}\text { Catedral de Gerona a B. Gra- } \\
\text { nell }\end{array}$} & 1.320 & \\
\hline & & \multicolumn{2}{|c|}{ Diferencia de cantidades } & & $271^{\mathrm{a}}$ \\
\hline & & & & Total & 24.598 \\
\hline
\end{tabular}

\begin{tabular}{|c|c|c|c|c|}
\hline \multirow{7}{*}{ 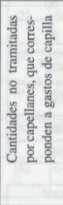 } & $\begin{array}{l}\text { Arcedia- } \\
\text { nato de } \\
\text { la Mar }\end{array}$ & & & $10.880^{c}$ \\
\hline & \multirow{2}{*}{ Tesorería } & Tesoreros & $8.3011 \mathrm{~d}$ & \multirow{2}{*}{$\begin{array}{c}11.889 \\
5 d^{f}\end{array}$} \\
\hline & & Otros funcionarios & $3.5884 d$ & \\
\hline & $\begin{array}{l}\text { Derecho } \\
\text { sello }\end{array}$ & \multirow{3}{*}{$\begin{array}{l}\text { Dinero utilizados para pagar el } \\
\text { sueldo a capellanes }\end{array}$} & 2.790 & \multirow{3}{*}{$4.449^{\mathrm{g}}$} \\
\hline & Tesoreros & & 1.177 & \\
\hline & $\begin{array}{l}\text { Otros } \\
\text { funciona- } \\
\text { rios }\end{array}$ & & 482 & \\
\hline & & & Total & $27.2185 \mathrm{~d}$ \\
\hline
\end{tabular}

a Véase cuadro 1.

b Asientos 2 a 14, 17,21, para los 3.011 \$ $9 \mathrm{~d}$; asientos 40 a 43, 45 para los 2.057 s $10 \mathrm{~d}$, asiento 19 para los $780 \mathrm{~s}$; asientos $15,16,18$ para los $609 \mathrm{~s} 5 \mathrm{~d}$.

c Véase cuadro de la pág. 24 y nota 40.

¿ Estos 271 sueldos corresponden a las diferencias siguientes:

1. Ingreso no contabilizado porque no llegó a realizarse . . . . . . . . . 1-260

2. Gastos de Berenguer Granell (nota 40$) \ldots \ldots \ldots \ldots \ldots \ldots \ldots \ldots \ldots$.

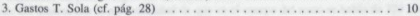

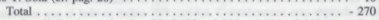

c Véase cuadros indicados en la pág. 23, $5.180+3.700+5.580-3.580$ (ya indicados en el cuadro anterior).

${ }^{\prime}$ Asientos [61] a [129]. (Faltan 60 sueldos para los 11.949 del total indicado porque no se han considerado los 60 del asiento [110], ya incluidos en el total de la nota c.)

g Asientos [130] a [145]. 
CUADRO 9

\begin{tabular}{|c|c|c|c|}
\hline $\begin{array}{l}\text { Tipo de proce- } \\
\text { dencia }\end{array}$ & $\begin{array}{l}\text { Tipos de fondos o nombre del } \\
\text { capellán interventor }\end{array}$ & Tipo de gastos & Valor \\
\hline \multirow{9}{*}{ 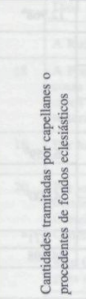 } & \multirow{2}{*}{ Fondos de la Mesa Episcopal } & Tesoreria & 4.000 \\
\hline & & Militares & $8.968^{a}$ \\
\hline & \multirow{3}{*}{$\begin{array}{l}\text { Fondos manejados por Juan } \\
\text { Martinez }\end{array}$} & Capilla & 2.962 \\
\hline & & del rey & $1.273^{b}$ \\
\hline & & Diversos & 425 \\
\hline & \multirow{4}{*}{$\begin{array}{l}\text { Fondos manejados } \\
\text { por Tomás Sola }\end{array}$} & Limosnas & $2.45210 \mathrm{~d}$ \\
\hline & & Rescate & $1.170^{\circ}$ \\
\hline & & Militares & 660 \\
\hline & & Transferencias & 1.365 \\
\hline & \multirow{5}{*}{$\begin{array}{l}\text { Fondos manejados } \\
\text { por Berenguer Granell }\end{array}$} & Limosnas & 60 \\
\hline & & Funerales & 30 \\
\hline \multirow[t]{3}{*}{ 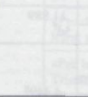 } & & Transferencias & $400^{d}$ \\
\hline & & Diversos & 168 \\
\hline & & Militares & 663 \\
\hline \multicolumn{3}{|c|}{ Total } & 24.598 \\
\hline
\end{tabular}

\begin{tabular}{|c|c|c|}
\hline \multirow{5}{*}{ 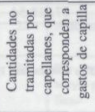 } & Pagos de sueldos a capellanes & $4.449^{c}$ \\
\hline & Gastos de capilla, limosnas y funeral & $11.8895 \mathrm{~d}$ \\
\hline & Gastos diversos & $1.700^{f}$ \\
\hline & Gastos militares y de rescate & 3.980 \\
\hline & Devolución de préstamos & 5.200 \\
\hline & Total & $27.2185 \mathrm{~d}$ \\
\hline
\end{tabular}

\footnotetext{
a Véase cuadro 1.

b Asientos [22] a [39] y ob. de las págs. 31 y 32.

c Asientos [130] a [145].

¿ Véase nota 52.

E Asientos [130] a [145].

( Asientos [61] a [129] y los 3 cuadros de las págs. 35 a 38.
} 
CUADRO 10

\begin{tabular}{|c|c|c|c|c|}
\hline Tipo de gasto & Valor parcial & $\%$ & Valor total & $\%$ \\
\hline Gastos de capilla & $17.39410 \mathrm{~d}$ & 36,6 & \multirow{2}{*}{$21.84310 \mathrm{~d}$} & \multirow{2}{*}{42,2} \\
\hline Sueldos a capellanes & 4.449 & 8,6 & & \\
\hline Transferencias & 5.765 & 11,1 & \multirow{5}{*}{$29.9727 d$} & \multirow{4}{*}{57.8} \\
\hline Gastos militares y rescates & 15.441 & 29,8 & & \\
\hline Devolución de préstamos & 5.200 & 10 & & \\
\hline Gastos del monarea & $1.2737 \mathrm{~d}$ & 2,5 & & \\
\hline Gastos diversos & 2.293 & 4,4 & & \\
\hline Total & $51.8165 \mathrm{~d}$ & 100 & $51.8165 \mathrm{~d}$ & 100 \\
\hline
\end{tabular}

\section{CUADRO 11}

\begin{tabular}{|c|c|c|c|c|}
\hline \multicolumn{5}{|c|}{ CUENTAS DEL CAPELLÁN JUÁN MARTINEZZ } \\
\hline & & INGRESOS & & \\
\hline $\begin{array}{l}\mathrm{N}^{\circ} \mathrm{de} \\
\text { orden }\end{array}$ & Fecha & Procedencia del dinero & Valor & Nota \\
\hline [1] & 64 feb. 5 & $\begin{array}{l}\text { De G. Setanti para los gastos de la } \\
\text { capilla }\end{array}$ & 260 & 1 \\
\hline [2] & 64 abr. 7 & $\begin{array}{l}\text { De F. Eanes para los gastos que se } \\
\text { indican }\end{array}$ & 329 & 2 \\
\hline [3] & 64 abr. 11 & $\begin{array}{l}\text { Del mismo para los gastos que se } \\
\text { indican }\end{array}$ & 63 & 3 \\
\hline [4] & 64 abr. 12 & $\begin{array}{l}\text { Del mismo para los gastos que se } \\
\text { indican }\end{array}$ & $9843 d$ & 4 \\
\hline [5] & 64 abr. 30 & $\begin{array}{l}\text { Del mismo para los gastos que se } \\
\text { indican }\end{array}$ & 120 & 5 \\
\hline [6] & 64 may. 5 & $\begin{array}{l}\text { Del mismo para los gastos que se } \\
\text { indican }\end{array}$ & 60 & 6 \\
\hline
\end{tabular}

1. Reg. 23, fol. Irl (carta no firmada ni por el rey ni por ningún funcionario).

2, Reg. 23, fol. 22vI (parcialmente publicada por J. COROLEU e INCLADA, «El condestable de Portugal, rey intruso de Cataluñas, Revista de Girona, vol. 2, 1878, p. 453, e integramente en nuestro estudio, citado en la nota 1 del texto, A assistência aos pobres; p. 436). Esta orden tuvo una primera redacción distinta (reg, 23, fol. 22rl), pero como se indica en el mismo registro fue substituida por otra, la que indicamos en primer lugar. En las cuentas de F. Eanes (MR, núm. 2489, fol. 69rII), estí registrada la salida del dinero, con la particularidad de que en el cuerpo del texto se habla de 329 sueldos (16 libras y 9 sueldos), mientras que al lado se indica 309 sueldos. Consideramos esta segunda referencia como un error, pos lo que apuatamos la cantidad de 329 sueldos, como manda el monarca.

3. Reg. 23, fol. 27vII y MR, núm. 2489, fol. 75rII.

4. Reg. 23, fol. 26v-27r (publicado en nuestro estudio, citado en la nota 1 del texto, $A$ assisténcia aos pobres, p. 436-437) y MR, núm, 2489, fol. 70 vII.

5. Reg. 23, fol. 34v-35r y MR, núm. 2489, fol. 76vil. El monarca habla de 126,5 sueldos, pero Fernando Eanes apenas registra la salida de 120

6. Reg. 23, fol. 38vIII y MR, nóm. 2489, fol. 106vIII. 


\section{CUADRO 11 (Continuación)}

\begin{tabular}{|c|c|c|c|c|}
\hline $\begin{array}{l}\mathrm{N}^{\circ} \text { de } \\
\text { orden }\end{array}$ & Fecha & Procedencia del dinero & Valor & Nota \\
\hline [7] & 64 may. 9 & $\begin{array}{l}\text { Del mismo para los gastos que se } \\
\text { indican }\end{array}$ & 260 & 7 \\
\hline [8] & 64 may. 11 & $\begin{array}{l}\text { Del mismo para los gastos que se } \\
\text { indican }\end{array}$ & $276 d$ & 8 \\
\hline [9] & 64 jun. 13 & $\begin{array}{l}\text { Del mismo para los gastos que se } \\
\text { indican }\end{array}$ & 24 & 9 \\
\hline$[10]$ & 64 jul. 15 & $\begin{array}{l}\text { Del mismo para los gastos que se } \\
\text { indican }\end{array}$ & $286 d$ & 10 \\
\hline [11] & 64 ago. 9 & $\begin{array}{l}\text { Del mismo para los gastos que se } \\
\text { indican }\end{array}$ & 27 & 11 \\
\hline [12] & 64 ago. 25 & $\begin{array}{l}\text { Del mismo para los gastos que se } \\
\text { indican }\end{array}$ & $476 d$ & 12 \\
\hline [13] & 64 sep. 18 & $\begin{array}{l}\text { Del mismo para los gastos que se } \\
\text { indican }\end{array}$ & 728 & 13 \\
\hline [14] & 64 oct. 26 & $\begin{array}{l}\text { Del mismo para los gastos que se } \\
\text { indican }\end{array}$ & 46 & 14 \\
\hline$[15]$ & 64 oct. 29 & $\begin{array}{l}\text { De J. Castelo Branco para los gastos } \\
\text { que se indican }\end{array}$ & $2925 d$ & 15 \\
\hline [16] & 64 die. 10 & $\begin{array}{l}\text { Del mismo para los gastos que se } \\
\text { indican }\end{array}$ & 41 & 16 \\
\hline$[17]$ & 64 dic. 11 & $\begin{array}{l}\text { De E. Eanes para los gastos que se } \\
\text { indican }\end{array}$ & 102 & 17 \\
\hline$[18]$ & 65 mar, 9 & $\begin{array}{l}\text { De B. Venrell para los gastos que el } \\
\text { rey mande }\end{array}$ & 276 & 18 \\
\hline [19] & 65 abr. 22 & $\begin{array}{l}\text { De L. Setanti para los gastos de un } \\
\text { viaje a Roma }\end{array}$ & 780 & 19 \\
\hline
\end{tabular}

7. Reg. 23, fol. 47 rll y MR, núm. 2489 , fol. 100 rII.

8. Reg 23, fol. 50 vIII y MR, núm. 2489, fol. 98 vII y 116 vIII.

9. Reg. 23, fol. 63vIll y MR, núm. 2489, fol. 122rill.

10. Reg. 23, fol. 80vi.

11. Reg. 23, fol, 80vII. Es la renovación de una anterior, del 3 de agosto (reg. 23, fol. 76rliI).

12. Reg. 23, fol. 93ri.

13. Reg. 23, fol. $164 v$.

14. Reg. 23, fol. 157vI.

15. Reg. 23, fol. 165r.

16. Reg. 23, fol. 178rII.

17. Reg. 23, fol. $178 \mathrm{v}-179 \mathrm{r}$.

18. Reg. 24, fol. 10vI.

19. Reg. 24, fol. 29rII. Como se comprueba por el registro de las cuentas de Luis Setanti (MR, nüm. 430, fol. $47 \mathrm{vI}$ ), el dinero sólo se entregará en mayo. Suponemos que está relacionada con otra carta dirigida a Juan Martinez el 25 del mismo mes de abril, en la cual el monarca le manda entregar a Juan Carrero el smig cofre que teniu nostre ab los arreus de la ginetar (reg. 24, fol. 31rIII). 


\section{CUADRO 11 (Continuación)}

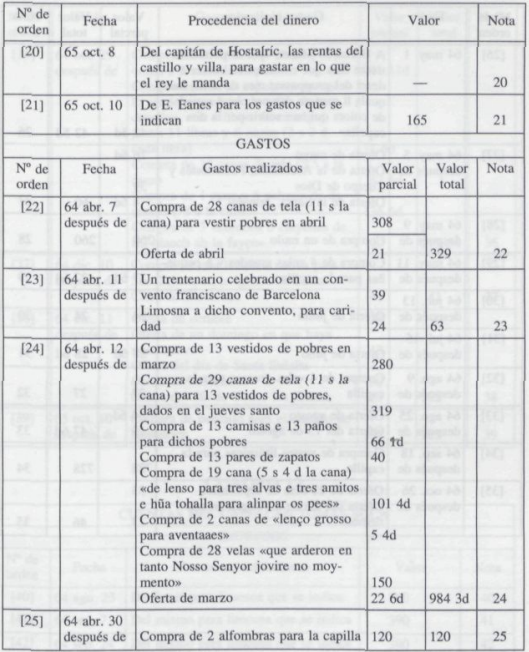

20. Reg. 61, fol. $12 \mathrm{ri}$

21. Reg. 24, fol. 110rI y MR, núm. 2490, fol. 132y-133r.

22. $[2]$

23. [5]

24. [4]. El rey se equivocó en las sumas porque babla de 2 d; en sus cuentas, F. Eanes, suma bien (3 s) y afima que estos preparativos son para las ceremonias de jueves santo.

25. [5] 
CUADRO 11 (Continuación)

\begin{tabular}{|c|c|c|c|c|c|}
\hline $\begin{array}{l}N^{0} \text { de } \\
\text { orden }\end{array}$ & Fecha & Gastos realizados & $\begin{array}{l}\text { Valor } \\
\text { parcial }\end{array}$ & $\begin{array}{l}\text { Valor } \\
\text { total }\end{array}$ & Nota \\
\hline$[26]$ & 64 may. 1 & $\begin{array}{l}\text { A Bernardo Mates, eper la porcio de } \\
\text { tretze dies que començaren correr a } \\
\text { deset del proppassat mes de abril, los } \\
\text { quals li manam dar per obs e servey } \\
\text { de colors qui han servir per la dita } \\
\text { capellas }\end{array}$ & $425 d$ & $425 d$ & 26 \\
\hline [27] & $\begin{array}{l}64 \text { may. } 5 \\
\text { después de }\end{array}$ & $\begin{array}{l}\text { Oferta de mayo } \\
\text { Oferta de la Ascensión, Pentecostés y } \\
\text { Cuerpo de Dios } \\
\text { Oferta de la Sanct. Trinidat }\end{array}$ & $\begin{array}{l}166 \mathrm{~d} \\
39 \\
46 \mathrm{~d}\end{array}$ & 60 & 27 \\
\hline [28] & $\begin{array}{l}64 \text { may. } 9 \\
\text { después de }\end{array}$ & Compra de un mulo & 260 & 260 & 28 \\
\hline [29] & $\begin{array}{l}64 \text { may. } 11 \\
\text { después de }\end{array}$ & $\begin{array}{l}\text { Compra de } 4 \text { velas grandes y } 6 \text { peque- } \\
\text { ñas para la capilla }\end{array}$ & $276 \mathrm{~d}$ & $276 \mathrm{~d}$ & 29 \\
\hline [30] & $\begin{array}{l}64 \text { jun. } 13 \\
\text { después de }\end{array}$ & Oferta de junio & 24 & 24 & 30 \\
\hline [31] & $\begin{array}{l}64 \text { jul, } 15 \\
\text { después de }\end{array}$ & Oferta de julio & $286 d$ & $286 \mathrm{~d}$ & 31 \\
\hline [32] & \begin{tabular}{|l|}
64 ago. 9 \\
después de
\end{tabular} & $\begin{array}{l}\text { Compra de } 4 \text { velas gruesas para la } \\
\text { capilla }\end{array}$ & 27 & 27 & 32 \\
\hline [33] & $\begin{array}{l}64 \text { ago. } 25 \\
\text { después de }\end{array}$ & $\begin{array}{l}\text { Oferta de agosto } \\
\text { Oferta del is de agosto }\end{array}$ & $\begin{array}{l}346 d \\
13\end{array}$ & $476 d$ & 33 \\
\hline$[34]$ & $\begin{array}{l}64 \text { sep. } 18 \\
\text { después de }\end{array}$ & $\begin{array}{l}\text { Compra de vestes litúrgicas para la } \\
\text { capilla }\end{array}$ & 728 & 728 & 34 \\
\hline [35] & $\begin{array}{l}64 \text { oct. } 26 \\
\text { después de }\end{array}$ & $\begin{array}{l}\text { Oferta de } 22 \text { días de septiembre } \\
\text { Oferta del día de la Virgen en sep- } \\
\text { tiembre }\end{array}$ & $\begin{array}{l}33 \\
13\end{array}$ & 46 & 35 \\
\hline
\end{tabular}

26. Reg, 23 , fol. 36 vII.

27. [6]

28. [7]

29. [8]

30. [9]

31. [10]

32. [11]

33. [12]

34. [13]

35. [14] 
CUADRO 11 (Continuación)

\begin{tabular}{|c|c|c|c|c|c|}
\hline $\begin{array}{l}N^{e} \text { de } \\
\text { orden }\end{array}$ & Fecha & Gastos realizados & $\begin{array}{c}\text { Valor } \\
\text { parcial }\end{array}$ & $\begin{array}{l}\text { Valor } \\
\text { total }\end{array}$ & Nota \\
\hline [36] & $\begin{array}{l}64 \text { oct. } 29 \\
\text { después de }\end{array}$ & $\begin{array}{l}\text { Compra de } 20 \text { velas ( } 19 \text { libras y } 4 \\
\text { onzas a } 2 \text { s } 2 \text { d la libra) } \\
\text { Compra de } 2 \text { velas rojas, «meses per } \\
\text { lo candelers, «fetes de refus de la } \\
\text { capellas, con } 4 \text { libras de cera que } \\
\text { pesan } 11 \text { libras y } 6 \text { onzas }(2 \mathrm{~s} 2 \text { d } \\
\text { cada libra) } \\
\text { Compra de } 15 \text { canas de tela ( } 5,5 \text { s la } \\
\text { cana) } \\
\text { Compra de } 1 \text { cana y } 6 \text { palmos de da- } \\
\text { masco ( } 78 \text { s la cana) } \\
\text { Compra de } 3 \text { «cordons o cinyelles de } \\
\text { fill blanch ab la fayço }\end{array}$ & $\begin{array}{l}116 d \\
826 d \\
1366 d \\
20\end{array}$ & $2925 d$ & 36 \\
\hline [37] & $\begin{array}{l}64 \text { dic. } 10 \\
\text { después de }\end{array}$ & $\begin{array}{l}\text { Compra de una lámpara votiva para } \\
\text { San Telmo, en la iglesia de Santa } \\
\text { Clara de Barcelona }\end{array}$ & 41 & 41 & 37 \\
\hline [38] & $\begin{array}{l}64 \text { dic. } 11 \\
\text { después de }\end{array}$ & $\begin{array}{l}\text { Oferta de octubre } \\
\text { Oferta de un domingo en que haya } \\
\text { misa nueva } \\
\text { Oferta del día de Santa Eulalia } \\
\text { Oferta de noviembre } \\
\text { Oferta del día de Todos los Santos }\end{array}$ & $\begin{array}{l}33 \\
13 \\
13 \\
30 \\
13\end{array}$ & 102 & 38 \\
\hline [39] & $\begin{array}{l}65 \text { oct. } 10 \\
\text { después de }\end{array}$ & $\begin{array}{l}\text { Compra de pescado para el castillo de } \\
\text { Hostalrich }\end{array}$ & 165 & 165 & 39 \\
\hline
\end{tabular}

\section{CUADRO 12}

\begin{tabular}{|c|c|c|c|c|}
\hline \multicolumn{5}{|c|}{ CUENTAS DEL CAPELLAN TOMÁS SOL.A } \\
\hline $\begin{array}{c}|c| \\
\mathrm{N}^{\circ} \text { de } \\
\text { orden }\end{array}$ & Fecha & Procedencia del dinero & Valor & Nota \\
\hline$[40]$ & 64 ago. 23 & De Eanes para limosna que se indica & 260 & 40 \\
\hline$[41]$ & 64 sep. 7 & Del mismo para limosna que se indica & 390 & 41 \\
\hline$[42]$ & 64 sep. 24 & Del mismo para limosna que se indica & 390 & 42 \\
\hline
\end{tabular}

39. [21]

40. Reg. 23 , fol. $92 \mathrm{rll}$.

41. Reg. 23, fol. 103vII.

42. Reg. 23 , fol. $123 \mathrm{r}-123 \mathrm{v}$. 


\section{CUADRO 12 (Continuación)}

\begin{tabular}{|c|c|c|c|c|c|}
\hline $\begin{array}{l}\mathrm{N}^{\circ} \text { de } \\
\text { orden }\end{array}$ & Fecha & \multicolumn{2}{|c|}{ Procedencia del dinero } & Valor & Nota \\
\hline [43] & 64 nov. 10 & \multicolumn{2}{|c|}{$\begin{array}{l}\text { Del mismo para la limosna que se } \\
\text { indica }\end{array}$} & $92110 \mathrm{~d}$ & 43 \\
\hline [44] & 65 ene/mar & \multicolumn{2}{|l|}{ Del Arcediano de la Mar } & 3.580 & 44 \\
\hline [45] & $65 \mathrm{oct}$ & \multicolumn{2}{|c|}{$\begin{array}{l}\text { De F. Eanes para la limosna que se } \\
\text { indica }\end{array}$} & 93 & 45 \\
\hline \multicolumn{6}{|c|}{ CUENTAS DEL CAPELLÁN TOMÁS SOLA } \\
\hline \multicolumn{6}{|c|}{ GASTOS } \\
\hline $\begin{array}{l}N^{\circ} \text { de } \\
\text { orden }\end{array}$ & Fecha & \multicolumn{2}{|c|}{ Gastos realizados } & Valor & Nota \\
\hline [46] & $\begin{array}{l}64 \text { ago. } 23 \\
\text { después de }\end{array}$ & \multicolumn{2}{|l|}{ Limosnas } & 260 & 46 \\
\hline$[47]$ & $\begin{array}{l}64 \text { sep. } 7 \\
\text { después de }\end{array}$ & \multicolumn{2}{|c|}{$\begin{array}{l}\text { A Ana Eulalia, hija de Antonio Rubí, } \\
\text { ciudadano de Barcelona, difunto, *per } \\
\text { reverencia de Deu per matrimonis }\end{array}$} & 390 & 47 \\
\hline$[48]$ & $\begin{array}{l}64 \text { sep. } 24 \\
\text { después de }\end{array}$ & \multicolumn{2}{|l|}{ Limosnas } & 390 & 48 \\
\hline \multirow[t]{2}{*}{ [49] } & \multirow{2}{*}{$\begin{array}{l}64 \text { nov. } 10 \\
\text { después de }\end{array}$} & $\begin{array}{l}\text { Limosnas hasta el } 29 \text { de } \\
\text { octubre }\end{array}$ & 624 s $10 d$ & \multirow[b]{2}{*}{$92410 \mathrm{~d}$} & \\
\hline & & Otras limosnas & $300 \mathrm{~s}$ & & 49 \\
\hline [50] & 65 feb, 12 & \multicolumn{2}{|c|}{ Al capellán Antonio Bonanat } & 1.200 & 50 \\
\hline
\end{tabular}

43. Reg. 23, fol, 163v-164r.

44. Véase cuadro de la p. 33.

45. Reg. 24, fol. 108ri MR, núm. 2490, fol. 140rl. Este pago tiene antecedentes que conviene referir. El 2 de septiembre de este año, el rey escribe a F. Eanes, mandándole dar a T. Sola 31 libras que les son debidas para la limosna (reg. 24 , fol. $92 \mathrm{vIII}$, publicado en nuestro estudio, citado en la nota 1 del texto, A assitência aos pobres, p. 437). El día 24 siguiente, el monarca autoriza T. Sola à que, de dichas 31 libras, rest 26 libras, 6 sueldos y 3 dineros, como sueldo de la administración de los bienes de sacerdotes rebeldes (véase nota 14 del texto y reg. 24, fol. 107 vIl, publicado en id., p. 438). Y, el mismo día, F. Eanes recibe orden de pagar a T. Sola 93 sueldos y 9 dineros para la limosna debida hasta el 29 de actubre (reg. 24, fol. 108rD), cantidad que corresponde exactamente a la cifra que resulta de la diferencia entre las 31 libras y las 26 libras, 6 sueldos y 3 dineros anteriormente referidos. Pero, de las 3 órdenes de pago citadas, sólo esta última se cumple; en las cuentas de F. Eanes apenas se registra, en el mes de octubre, la salida de 93 sueldos para T. Sola, eper causa de la almoyna», segün orden real fechada del 24 de septiembre.

46. $[40]$

47. $[41]$

48. [42]

49. [43]

50. Reg. 24, fol. IvIV. Según el monarea, el dinero a pagar sería retirado de los fondos confiseados a sacerdotes rebeldes (véase nota 14 del texto), asi como los pagos indicados en los asientos [51], [52], [53]. Pero, como se indica en el texto (véase p. 27, el dinero vendrá del Arcedianato de la Mar. 


\section{CUADRO 12 (Continuación)}

\begin{tabular}{|c|c|c|c|c|}
\hline $\begin{array}{l}\mathrm{N}^{\circ} \text { de } \\
\text { orden }\end{array}$ & Fecha & Gastos realizados & Valor & Nota \\
\hline [51] & 65 feb. 24 & $\begin{array}{l}\text { A Pedro de Miranda para gastar en } \\
\text { servicio del Principado }\end{array}$ & 660 & 51 \\
\hline [52] & $65 \operatorname{mar} .8$ & Resta para pagar su rescate & 1.170 & 52 \\
\hline [53] & 65 mar. 9 & $\begin{array}{l}\text { Al capellan A.J. Alago para comprar } \\
\text { una ecloxas }\end{array}$ & 165 & 53 \\
\hline [54] & 65 may. 20 & $\begin{array}{l}\text { A Saneho de Sarama eper distribuir } \\
\text { per la anima de un son parent que vuy } \\
\text { es mort en nostre servey» }\end{array}$ & 55 & 54 \\
\hline$[55]$ & 65 may. 21 & $\begin{array}{l}\text { Al presbitero Juan Rabes, por amor de } \\
\text { Dios }\end{array}$ & 55 & 55 \\
\hline [56] & 65 jun. 3 & $\begin{array}{l}\text { A } 5 \text { capellanes que han dicho } 5 \text { trente- } \\
\text { narios, } 30 \text { s a cada una, por caridad }\end{array}$ & 150 & 56 \\
\hline [57] & 65 jun. 13 & $\begin{array}{l}\text { A Juan Torres, por su enfermedad, por } \\
\text { amor de Dios }\end{array}$ & 30 & 57 \\
\hline [58] & 65 jun. 17 & $\begin{array}{l}\text { Al espingardero Simón, por su enfer- } \\
\text { medad }\end{array}$ & 45 & 58 \\
\hline$[59]$ & 65 jun. 30 & $\begin{array}{l}\text { A G. Martí, de la compañía de los } \\
\text { borguiñones, por caridad }\end{array}$ & 60 & 59 \\
\hline$[60]$ & 65 oct. & Limosnas hasta el 29 de octubre & 93 & 60 \\
\hline
\end{tabular}

\section{CUADRO 13}

Relación de gastos propios de una capellanía real que no son tramitados por las manos de los capellanes

\begin{tabular}{|c|c|c|l|c|l|}
\hline $\begin{array}{c}\mathrm{N}^{0} \text { de } \\
\text { orden }\end{array}$ & \multicolumn{1}{|c|}{ Fecha } & Procedencia & Tipo de gasto & Valor & \multicolumn{1}{|c|}{ Fuente } \\
\hline$[61]$ & 64 feb. 5 & Fernando Eanes & Limosna & 39 & A pobreza, 1 \\
\hline$[62]$ & 64 feb. 27 & Fernando Eanes & Limosna & 39 & A pobreza, 2 \\
\hline
\end{tabular}

51. Reg. 24, fol. 5 III vd, nota anterior).

52. Reg. 24, fol. 8vII.

53. Reg, 24, fol. 11vI.

54. Reg. 24. fol. 40vIJ]

55. Reg. 24, fol. 41vIII.

56. Reg. 24, fol. 47rll.

57. Reg. 24 , fol. $52 \mathrm{v}-53 \mathrm{r}$.

58. Reg. 24, fol. $56 \mathrm{rll}$.

59. Reg. 24, fol. 63vII.

60. [45] 
CUADRO 13 (Continuación)

\begin{tabular}{|c|c|c|c|c|c|c|}
\hline $\begin{array}{l}\mathrm{N}^{\circ} \text { de } \\
\text { orden }\end{array}$ & Fecha & Procedencia & \multicolumn{2}{|c|}{ Tipo de gasto } & Valor & Fuente \\
\hline [63] & 64 feb. 29 & Fernando Eanes & \multicolumn{2}{|c|}{ Limosna } & 65 & A pobreza, 3 \\
\hline$[64]$ & 64 mar. 22 & Rentas diversas & \multicolumn{2}{|c|}{ Limosna } & 260 & A pobreza, 4 \\
\hline [65] & 64 mar. 30 & Guiller. Setanti & \multicolumn{2}{|c|}{ Limosna } & 221 & A pobreza, 5 \\
\hline \multirow[t]{2}{*}[66]{} & \multirow[t]{2}{*}{64 abr. 9} & \multirow[t]{2}{*}{ Fernando Eanes } & \multicolumn{2}{|c|}{ Vestir cap. } & $12710 d$ & \multirow{2}{*}{$\begin{array}{l}\text { Reg. } 23 \text {, fol. } 25 \mathrm{r}- \\
25 \mathrm{v} \text { : MR. } 2489 \text {, } \\
\text { fol. } 69 \mathrm{v}-70 \mathrm{r}\end{array}$} \\
\hline & & & \multicolumn{2}{|c|}{ Gastos cap. } & $1253 \mathrm{~d}$ & \\
\hline [67] & 64 abr. 10 & Fernando Eanes & \multicolumn{2}{|c|}{ Limosna } & 390 & A pobreza, 7 \\
\hline$[68]$ & 64 abr. 17 & Fernando Eanes & \multicolumn{2}{|c|}{$\begin{array}{l}\text { Misas por fu- } \\
\text { neral }\end{array}$} & 100 & $\begin{array}{l}\text { Reg. } 23 \text {, fol. } 28 \text { - } \\
\text { vIII; MR. } 2489 \text {, } \\
\text { fol. } 71 \mathrm{r}-71 \mathrm{v}\end{array}$ \\
\hline [69] & 64 abr. 21 & Fernando Eanes & \multicolumn{2}{|c|}{ Limosna } & 156 & A pobreza, 10 \\
\hline \multirow[t]{3}{*}[70]{} & \multirow[t]{3}{*}{64 abr. 28} & \multirow[t]{3}{*}{ Fernando Eanes } & Lim. & $166 \mathrm{~d}$ & \multirow{3}{*}{$3243 d$} & \multirow{3}{*}{$\begin{array}{l}\text { Reg. } 23, \text { fol. } \\
43 v-44 r ; \text { MR. } \\
2489, \text { fol. } 78 v\end{array}$} \\
\hline & & & \multirow{2}{*}{$\begin{array}{l}\text { Gas- } \\
\text { tos } \\
\text { capi- } \\
\text { lla }\end{array}$} & & & \\
\hline & & & & $3079 \mathrm{~d}$ & & \\
\hline [71] & 64 jun. 3 & Fernando Eanes & \multicolumn{2}{|c|}{ Limosna } & 132 & A pobreza, 13 \\
\hline [72] & 64 jun. 5 & Fernando Eanes & \multicolumn{2}{|c|}{ Limosna } & $106 d$ & A pobreza, 14 \\
\hline$[73]$ & 64 jun. 8 & Fernando Eanes & \multicolumn{2}{|c|}{$\begin{array}{l}\text { Gastos por } \\
\text { funerales }\end{array}$} & $10686 d$ & $\begin{array}{l}\text { Reg. } 23 \text {, fol. } 62 \mathrm{r}- \\
62 \mathrm{v} \text {; MR. } 2489 \text {, } \\
\text { fol. } 121 \mathrm{vIV}\end{array}$ \\
\hline [74] & 64 jun. 19 & Fernando Eanes & \multicolumn{2}{|c|}{ Limosna } & 390 & A pobreza, 16 \\
\hline$[75]$ & 64 jul. 6 & Fernando Eanes & \multicolumn{2}{|c|}{ Limosna } & 390 & A pobreza, 17 \\
\hline$[76]$ & 64 jul. 13 & Fernando Eanes & \multicolumn{2}{|c|}{ Misa fun. } & 33 & $\begin{array}{l}\text { Reg. } 23, \text { fol. } \\
77 v-78 r\end{array}$ \\
\hline [77] & 64 ago. 16 & Fernando Eanes & \multicolumn{2}{|c|}{ Limosna } & 117 & A pobreza, 19 \\
\hline$[78]$ & 64 sep. 13 & Fernando Eanes & \multicolumn{2}{|c|}{ Misa fun. } & 30 & $\begin{array}{l}\text { Reg. 23, fol. } \\
127 \mathrm{v}-128 \mathrm{r}\end{array}$ \\
\hline [79] & 64 sep. 14 & Rentas de Jtalia & \multicolumn{2}{|c|}{ Limosna } & $(*)$ & A pobreza, 23 \\
\hline [80] & 64 sep. 25 & Fernando Eanes & \multicolumn{2}{|c|}{ Limosna } & 77 & A pobreza, 25 \\
\hline [81] & 64 sep. 27 & Fernando Eanes & \multicolumn{2}{|c|}{ Limosna } & 65 & A pobreza, 26 \\
\hline [82] & 64 oct. 26 & Fernando Eanes & \multicolumn{2}{|c|}{ Limosna } & 76 & A pobreza, 29 \\
\hline [83] & 64 nov. 22 & J. Castelo Branco & \multicolumn{2}{|c|}{ Limosna } & 117 & A pobreza, 33 \\
\hline [84] & 64 dic. 21 & J. Castelo Branco & \multicolumn{2}{|c|}{ Limosna } & 91 & A pobreza, 34 \\
\hline
\end{tabular}

* El texto manda dar 14 ducados de la camera; como peceden de las rentas italianas del monarca, no los hemos contabilizado. 
CUADRO 13 (Continuación)

\begin{tabular}{|c|c|c|c|c|c|}
\hline $\begin{array}{l}\mathrm{N}^{*} \text { de } \\
\text { orden }\end{array}$ & Fecha & Procedencia & Tipo de gasto & Valor & Fuente \\
\hline [86] & 65 abr. 9 & Bereng. Venrell & Limosna & 330 & A pobreza, 36 \\
\hline [87] & 65 abr. 21 & Rent. confiscadas & Limosna & 660 & A pobreza, 37 \\
\hline [88] & 65 abr. 28 & Bereng. Venrell & Oferta rel & 550 & Reg. 24, fol. 33rI \\
\hline [89] & 65 may. 4 & Bereng. Venrell & Velas cap. & $24410 d$ & Reg. 24, fol, 36rI \\
\hline [90] & 65 jul, 20 & Berenguer Palau & Limosna & 100 & A pobreza, 44 \\
\hline [91] & 65 jul. 20 & Fernando Eanes & Limosna & 203 & A pobreza, 45 \\
\hline [92] & 65 jul. 22 & Alfonso Obidos & Limosna & 132 & A pobreza, 46 \\
\hline [93] & 65 jul. 24 & Alfonso Obidos & Oferta rel & 20 & A pobreza, 47 \\
\hline [94] & 65 sep. 4 & Fernando Eanes & Limosna & 90 & A pobreza, 49 \\
\hline [95] & 65 sep. 6 & Fernando Eanes & Limosna & 55 & A pobreza, 50 \\
\hline [96] & 65 sep. 7 & Fernando Eanes & Limosna & 12 & A pobreza, 51 \\
\hline [97] & 65 sep. 8 & Femando Eanes & Limosna & $76 d$ & A pobreza, 52 \\
\hline [98] & 65 sep. 24 & Fernando Eanes & Limosna & $106 \mathrm{~d}$ & A pobreza, 53 \\
\hline [99] & 65 oct. & Fernando Eanes & Limosna & 132 & $\begin{array}{l}\text { MR., 2490, fol. } \\
\text { 139rI }\end{array}$ \\
\hline$[100]$ & 65 0ct. 1 & \begin{tabular}{|l|} 
Alfonso Obidos y \\
Fernando Eanes
\end{tabular} & $\begin{array}{l}\text { Medicinas y } \\
\text { misas fun. }\end{array}$ & 154 & $\begin{array}{l}\text { Reg. } 24, \text { fol. } 10 \\
4 \mathrm{vI} ; \text { y } 181 \mathrm{r}-181 \mathrm{v}\end{array}$ \\
\hline [101] & 65 oct. 7 & Fernando Eanes & Oferta 27 & & \multirow{2}{*}{$\begin{array}{l}\text { Reg. } 24, \text { fol. } \\
\text { 180rI: MR. } \\
\text { 2490, fol. } 128 \text { rII } \\
\end{array}$} \\
\hline & & 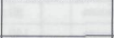 & jul. $/ 7$ oct. & 123 & \\
\hline$[102]$ & 65 oct. 9 & Fernando Eanes & Oferta rel & 330 & $\begin{array}{l}\text { Reg. 24, fol. } \\
182 \mathrm{vI} ; \text { MR. } \\
2490, \text { fol. } 135 \text { III }\end{array}$ \\
\hline [103] & 65 oct. 9 & Fernando Eanes & Oferta rel & 180 & $\begin{array}{l}\text { MR. 2490, fol. } \\
\text { 124ril }\end{array}$ \\
\hline [104] & 65 oct 9 & Femando Eanes & Limosna & 480 & $\begin{array}{l}\text { Reg, } 24, \text { fol. } \\
182 \mathrm{rII} ; \mathrm{MR} \text {. } \\
2490 \text {, fol, } 128 \mathrm{v}- \\
129 \mathrm{r}\end{array}$ \\
\hline [105] & 65 oct. 9 & Fernando Eanes & Velas cap. & 66 & $\begin{array}{l}\text { Reg. } 24, \text { fol. } \\
\text { 109rIII; MR. } \\
\text { 2490, fol. } 121 \text { rII }\end{array}$ \\
\hline [106] & 65 oct. 13 & Nicolas Company & Rescate & 110 & A pobreza, 57 \\
\hline [107] & 65 oct. 17 & Fernando Eanes & Limosna & 660 & A pobreza, 58 \\
\hline [108] & 65 nov. 10 & Juan Stela & Gastos capilla & 330 & $\begin{array}{l}\text { 2Reg, 24, fol. } \\
116 \mathrm{r}-116 \mathrm{v} ; \mathrm{MR} \text {. } \\
\text { 433, fol. 27rII }\end{array}$ \\
\hline
\end{tabular}


CUADRO 13 (Continuación)

\begin{tabular}{|c|c|c|c|c|c|}
\hline $\begin{array}{l}\mathrm{N}^{\circ} \text { de } \\
\text { orden }\end{array}$ & Fecha & Procedencia & Tipo de gasto & Valor & Fuente \\
\hline [109] & 65 dic. & Juan Stela & Gastos capilla & $2799 \mathrm{~d}$ & $\begin{array}{l}\text { MR. } 433, \text { fol. } \\
\text { 27ril }\end{array}$ \\
\hline [110] & 65 dic, 17 & $\begin{array}{l}\text { rentas eclesiásti- } \\
\text { cas }\end{array}$ & Limosna & 60 & $\begin{array}{l}\text { A pobreza, } 59 \text { y } \\
\text { nota } 52 \text { del texto }\end{array}$ \\
\hline [111] & 66 ene. & Juan Stela & Gastos capilla & 62 & $\begin{array}{l}\text { MR. } 433 \text {, fol. } \\
144 \mathrm{vII}\end{array}$ \\
\hline$[112]$ & 66 ene. 6 & Nicolás Company & Limosna & 9 & $\begin{array}{l}\text { Reg. } 24 \text {, fol. } \\
\text { 144vII }\end{array}$ \\
\hline [113] & 66 ene. 9 & Nicolás Company & Limosna & 100 & A pobreza, 60 \\
\hline$[114]$ & 66 ene. 10 & Nicolás Company & Limosna & 6 & A pobreza, 61 \\
\hline$[115]$ & 66 ene, 28 & Juan Vicente & Limosna & 50 & A pobreza, 62 \\
\hline [116] & 66 ene. 29 & Juan Vicente & Limosna & 84 & A pobreza, 63 \\
\hline [117] & 66 feb. 7 & Juan Farinha & Limosna & 50 & A pobreza, 65 \\
\hline [118] & 66 feb. 19 & Juan Vicente & Limosna & 30 & A pobreza, 66 \\
\hline [119] & 66 mar. 3 & Juan Farinha & Limosna & 60 & A pobreza, 68 \\
\hline$[120]$ & 66 mar. 5 & Juan Farinha & Limosna & 60 & $\begin{array}{l}\text { Reg. 24, fol. } \\
150 \mathrm{rI}\end{array}$ \\
\hline$[121]$ & 66 mar. 10 & Juan Farinha & Misa fun. & 30 & $\begin{array}{l}\text { Reg. 24, fol. } \\
\text { 214ril }\end{array}$ \\
\hline [122] & 66 mar. 16 & Juan Farinha & Limosna & 30 & A pobreza, 69 \\
\hline [123] & 66 abr. 7 & Alfonso Obidos & Limosna & 140 & A pobreza, 71 \\
\hline [124] & 66 abr. 12 & Pedro Dezpla & Limosna & 600 & A pobreza, 72 \\
\hline [125] & 66 abr. 12 & Nicolás Company & Limosna & $1266 \mathrm{~d}$ & A pobreza, 73 \\
\hline$[126]$ & 66 abr. 15 & Nicolás Company & Gastos capilla & 1 & $\begin{array}{l}\text { Reg. 24, fol. } \\
159 \text { vIII }\end{array}$ \\
\hline [127] & 66 abr. 18 & Rodrigo Vidal & Misas & 20 & $\begin{array}{l}\text { Reg. 24, fol, } \\
\text { 219vil }\end{array}$ \\
\hline [128] & 66 may. 15 & Pedro Dezpla & Limosna & 550 & A pobreza, 74 \\
\hline [129] & 66 jun. 8 & A. Montserrate & Limosna & 60 & A pobreza, 75 \\
\hline & & & Total & $1.949 \mathrm{sd}$ & \\
\hline
\end{tabular}


CUADRO 14

\begin{tabular}{|c|c|c|c|c|c|c|}
\hline \multicolumn{7}{|c|}{ Sueldos pagados a capellanes } \\
\hline & Fecha & Fuente & Procedencia & Valor & Nombre del capellan & Valor \\
\hline \multirow[t]{3}{*}{ [130] } & \multirow[t]{3}{*}{64 abr. 17} & \multirow{3}{*}{$\begin{array}{l}\text { Reg. 23, fol. } \\
121 \mathrm{r}-121 \mathrm{v}\end{array}$} & \multirow[t]{3}{*}{ Rodrigo Vidal } & \multirow[t]{3}{*}{490} & A.J. Alago & 165 \\
\hline & & & & & Tomás Sola & 195 \\
\hline & & & & & Fernando Vaz & 130 \\
\hline \multirow[t]{2}{*}{ [131] } & \multirow[t]{2}{*}{64 may. } & \multirow{2}{*}{$\begin{array}{l}\text { MR, } 2489 \\
\text { fol. } 107 \mathrm{rI}\end{array}$} & \multirow[t]{2}{*}{ Fernando Eanes } & \multirow{2}{*}{132} & Juan Darmes & 77 \\
\hline & & & & & Vasco Gil & 55 \\
\hline \multirow{6}{*}{ [132] } & \multirow[t]{6}{*}{64 may. 8} & \multirow{6}{*}{$\begin{array}{l}\text { Reg. 23, fol. } \\
121 \mathrm{v}\end{array}$} & \multirow[t]{6}{*}{ Rodrigo Vidal } & \multirow[t]{6}{*}{624} & \begin{tabular}{|l|} 
Juan Martínez \\
\end{tabular} & 104 \\
\hline & & & & & \begin{tabular}{|l} 
Sancho Vallobar \\
\end{tabular} & 104 \\
\hline & & & & & Gabricl Agras & 104 \\
\hline & & & & & Ramón Sala & 104 \\
\hline & & & & & Bernardo Mates & 104 \\
\hline & & & & & Claudo & 104 \\
\hline [133] & 64 may. 20 & $\begin{array}{l}\text { Reg. 23, fol. } \\
55 \mathrm{vII} \text {; MR, } \\
2489 \text {, fol. } \\
105 \mathrm{vI}\end{array}$ & Fernando Eanes & 110 & Bernardo Mates & 110 \\
\hline [134] & 64 jun. 3 & $\begin{array}{l}\text { Reg. 23, fol. } \\
59 \mathrm{vII}\end{array}$ & Rodrigo Vidal & 65 & $\begin{array}{l}\text { Pedro Miguel, «es- } \\
\text { cola de la almoyna } \\
\text { nostra» }\end{array}$ & 65 \\
\hline \multirow{8}{*}{ [135] } & \multirow[t]{8}{*}{64 jun. 25} & \multirow{8}{*}{$\begin{array}{l}\text { Reg. 23, fol. } \\
68 \text { vII }\end{array}$} & \multirow[t]{8}{*}{ Rodrigo Vidal } & \multirow[t]{8}{*}{792} & Fernando Vaz & 99 \\
\hline & & & & & \begin{tabular}{|l} 
Juan Martínez \\
\end{tabular} & 99 \\
\hline & & & & & \begin{tabular}{|l} 
Sancho Vallobar \\
\end{tabular} & 99 \\
\hline & & & & & Gabriel Agras & 99 \\
\hline & & & & & Ramón Sala & 99 \\
\hline & & & & & \begin{tabular}{|l} 
A.J. Alago \\
\end{tabular} & 99 \\
\hline & & & & & \begin{tabular}{|l|} 
Bernardo Mates \\
\end{tabular} & 99 \\
\hline & & & & & Claudo & 99 \\
\hline \multirow[t]{8}{*}{ [136] } & \multirow[t]{8}{*}{64 sep. 11} & \multirow{8}{*}{$\begin{array}{l}\text { Reg. } 23, \text { fol. } \\
108 r-108 v\end{array}$} & \multirow[t]{8}{*}{ Rodrigo Vidal } & \multirow[t]{8}{*}{792} & Juan Martínez & 104 \\
\hline & & & & & \begin{tabular}{|l|} 
Vasco Gil \\
\end{tabular} & 65 \\
\hline & & & & & Sancho Vallobar & 104 \\
\hline & & & & & Gabriel Agras & 104 \\
\hline & & & & & Claudo & 104 \\
\hline & & & & & \begin{tabular}{|l|} 
Bernardo Mates \\
\end{tabular} & 130 \\
\hline & & & & & Ramón Sala & 104 \\
\hline & & & & & A.J. Alago & 104 \\
\hline
\end{tabular}


CUADRO 14 (Continuación)

\begin{tabular}{|c|c|c|c|c|c|c|}
\hline & Fecha & Fuente & Procedencia & Valor & Nombre del capellán & Valor \\
\hline [137] & 65 abr. 15 & $\begin{array}{l}\text { Reg. 24, fol. } \\
28 \text { rIV }\end{array}$ & Ber. Venrell & 330 & Fernando Vaz & 330 \\
\hline [138] & 65 abr. 25 & $\begin{array}{l}\text { Reg. 24, fol. } \\
32 \text { rill }\end{array}$ & Ber. Venrell & 132 & Rodrigo Eanes & 132 \\
\hline [139] & 65 jun. 4 & $\begin{array}{l}\text { Reg. } 24, \text { fol, } \\
47 \mathrm{rIII} \text {; MR, } \\
2490, \text { fol. } \\
94 \mathrm{rIII}\end{array}$ & Fernando Eanes & 50 & $\begin{array}{l}\text { Antonio Centra y un } \\
\text { fraile, su compañero }\end{array}$ & 50 \\
\hline \multirow[t]{2}{*}[140]{} & \multirow[t]{2}{*}{65 jul. 17} & \multirow{2}{*}{$\begin{array}{l}\text { Reg. } 24 \text {, fol. } \\
74 \mathrm{vIV} \text {; MR, } \\
2490 \text {, fol. } \\
99 \mathrm{r}-99 \mathrm{v}\end{array}$} & \multirow[t]{2}{*}{ Fernando Eanes } & \multirow[t]{2}{*}{100} & Bartol. Peyro & 60 \\
\hline & & & & & P.L. Gagos & 40 \\
\hline \multirow[t]{2}{*}{ [141] } & \multirow[t]{2}{*}{65 jul. 19} & \multirow{2}{*}{$\begin{array}{l}\text { Reg. } 24, \text { fol. } \\
75 \mathrm{rI} ; \text { MR, } \\
\text { 2490, fol. } \\
\text { 100vIII }\end{array}$} & \multirow[t]{2}{*}{ Fernando Eanes } & \multirow[t]{2}{*}{100} & Bernardo Mates & 60 \\
\hline & & & & & Ramón Sala & 40 \\
\hline \multirow[t]{2}{*}{ [142] } & 65 ago. 15 & $\begin{array}{l}\text { Reg. } 24, \text { fol. } \\
87 \mathrm{vI} \text {; MR, } \\
2490, \text { fol. }\end{array}$ & \multirow[t]{2}{*}{ Fernando Eanes } & \multirow[t]{2}{*}{330} & Antonio Cendra & 330 \\
\hline & 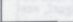 & $104 \mathrm{vIII}$ & & & 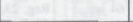 & \\
\hline [143] & 65 sep. 4 & $\begin{array}{l}\text { Reg. } 24, \text { fol. } \\
96 \mathrm{rII} \text {; MR, } \\
2490 \text {, fol. } \\
115 \mathrm{v}-116 \mathrm{r}\end{array}$ & Fernando Eanes & 55 & Pedro Vaz & 55 \\
\hline [144] & 66 abr. 15 & $\begin{array}{l}\text { Reg. 24, fol. } \\
\text { 160rII }\end{array}$ & $\begin{array}{l}\text { Nicolás Com- } \\
\text { pany }\end{array}$ & 20 & $\begin{array}{l}2 \text { chantres de la } \\
\text { capilla }\end{array}$ & 20 \\
\hline \multirow[t]{2}{*}{ [145] } & 66 jun. 7 & $\begin{array}{l}\text { Reg. } 24, \text { fol. } \\
228 \text { vIII }\end{array}$ & Pedro Dezpla & 300 & Antonio Cendra & 300 \\
\hline & & & TOTAL & 4449 & & 4449 \\
\hline
\end{tabular}

